\title{
LA DEMOCRACIA INCOMPLETA EN CHILE: LA REALIDAD TRAS LOS RANKINGS INTERNACIONALES *
}

\author{
Incomplete Democracy in Chile: Reality Behind International \\ Rankings
}

\author{
MANUEL ANTONIO GARRETÓN M. \\ Departamento Sociología Facultad de Ciencias Sociales Universidad de Chile
}

\section{ROBERTO GARRETÓN}

Abogado de libre ejercicio

\begin{abstract}
RESUMEN
A pesar de la imagen generalizada del caso chileno en los rankings internacionales como un proceso ejemplar de transición hacia la democracia y de la vida política democrática, Chile es una "democracia incompleta" debido a los enclaves autoritarios heredados de la dictadura y no superados en su totalidad. La democracia chilena, analizada a través de las dimensiones constitucional, electoral y ciudadana, presenta la contradicción entre los grandes avances conseguidos bajo los gobiernos de la Concertación y las debilidades en las tres dimensiones. Estas debilidades se explican por los límites fundantes en la soberanía popular observados a partir de la Constitución, que consagró la exclusión política a través del sistema binominal, de lo que se derivan los límites de la democracia electoral sujeta a restricciones fácticas y normativas en un diseño institucional deficiente. Asimismo, la dimensión ciudadana de la democracia se enfrenta a problemas de derechos civiles específicos de las minorías, desigualdades socioeconómicas, participación electoral y ausencia de instituciones de participación.
\end{abstract}

Palabras clave: Chile, democracia incompleta, enclaves autoritarios, sistema binominal, desigualdad, participación.

\begin{abstract}
Chile has a very good image on international rankings about its transition to democracy and democratic performance. Despite it, the Chilean case is still a case of incomplete democracy, due to the authoritarian enclaves inherited from the military dictatorship and not yet totally overcome. Analyzed through constitutional, electoral and citizen dimensions of democracy, the Chilean one shows a contradiction between the significant achievements under Concertacion government in almost twenty years and the weaknesses of this three dimensions. These weaknesses originated in the limits to popular sovereignty grounded on the Constitution where it was consecrated political exclusions through the electoral bi-nominal system. This generated an institutional design which leads to severe restrictions both factual and normative in political participation. Finally, the citizen dimension of democracy confronts several problems concerning civil rights of minorities, socio-economic inequalities, electoral participation and lack of social participation institutions.
\end{abstract}

Key words: Chile, incomplete democracy, authoritarian enclaves, bi-nominal system, inequalities, participation.

* Con la colaboración de Luis Garrido Vergara. 


\section{INTRODUCCIÓN}

Este estudio sobre el estado de la democracia en Chile contrasta con la imagen generalizada de la transición ejemplar o de los primeros puestos en todos los rankings de democracia que circulan en organismos y estudios internacionales. El estudio del estado de la democracia en las tres dimensiones (constitucional, electoral y ciudadana) ${ }^{1}$ que propone la Red de Investigación de la Democracia Andina (en adelante el Proyecto RIDA), se hace aquí a partir de la hipótesis central de democracia incompleta. Ésta se caracterizaría por las herencias institucionales del régimen militar y las tensiones que ello provoca en el funcionamiento democrático durante los gobiernos de la Concertación de Partidos por la Democracia, coalición que ha gobernado el país desde la recuperación democrática en 1990. Con ello se busca ir más allá de responder a una lista de preguntas o de la descripción y evaluación de una serie de indicadores, intentando explicar el origen, evolución y significado de éstos en el marco de la problemática propia del modelo político chileno de democracia vigente hoy.

El presente trabajo intenta contestar, de un modo global y relativamente en forma sistemática, las preguntas del marco metodológico del Proyecto, ligando todas las respuestas entre sí desde tres perspectivas y para cada una de las tres dimensiones de la democracia: constitucional, electoral y ciudadana. La primera, de carácter jurídicoinstitucional, es la contrastación, para los diversos ítems relevantes, entre el marco normativo chileno y sus variaciones en la época democrática postdictatorial con el marco normativo establecido por las Cartas o Declaraciones Internacionales en la materia. La segunda dimensión se refiere al estudio de las dinámicas propiamente políticas, tanto con respecto a los procesos como a las políticas públicas en las tres dimensiones, es decir, a lo que podríamos llamar el funcionamiento democrático. La tercera, de tipo evaluativo-normativo, se refiere a los efectos que estas dinámicas políticas han generado en la sociedad, al debate en torno a ellas y a las propuestas de reforma posible, con lo que esperamos contribuir también a los temas de profundización de la democracia en la región y mejorar su calidad.

En la parte de contexto se desarrollan las hipótesis de nuestro estudio y en las partes siguientes se analizan las tres dimensiones de la democracia a partir de entrevistas, documentos, trabajos previos de los propios autores y un encuentro con la sociedad civil. ${ }^{2}$ En cada una de estas partes se hace una breve introducción que plantea la derivación para cada una de ellas de la dimensión de la hipótesis general. En la conclusión intentamos dar una visión de conjunto que permite ratificar la hipótesis de democracia incompleta.

1 Si bien pensamos que la dimensión electoral debiera denominarse dimensión política, incluyendo la dimensión electoral y la participación ciudadana en decisiones públicas, y la dimensión ciudadana debiera incluir los aspectos vinculados a los derechos y a la participación en la sociedad civil, hemos mantenido la denominación y contenido de estas tres dimensiones establecida en el marco metodológico del Proyecto RIDA, aunque hemos alterado el orden de ellas, por considerar que la dimensión constitucional es la fundamental en relación a las otras.

2 Se trata del Taller "Democracia Chilena: Algunos temas pendientes", 8 de enero de 2009, organizado por la Corporación Participa en el marco del Proyecto RIDA. 


\section{EL CONTEXTO}

Nuestra hipótesis central es que estamos frente a una democracia incompleta, como resultado de la transición desde la dictadura de Pinochet ocurrida a finales de los ochenta. ${ }^{3}$ No es que no se haya terminado la transición, como sostienen algunos, o que hubiera terminado, ya sea en el gobierno de Lagos o de Bachelet, sino que si bien ella terminó con la inauguración del gobierno del Presidente Aylwin, lo que quedó después de esa transición, e incluso pese a ciertas reformas políticas implantadas por los gobiernos democráticos, fue esta democracia incompleta en las tres dimensiones: electoral, constitucional y ciudadana. Lo que explicaría tal caracterización es que la institucionalidad de la democracia chilena fue en gran parte impuesta por la dictadura, por lo que estaríamos frente a gobiernos elegidos de manera legítima, vigencia de libertades públicas, es decir, lo que podríamos llamar una "situación" democrática, ${ }^{4}$ pero difícilmente el régimen institucional en cuanto tal pasaría el test democrático. Tampoco se trata únicamente de lo que se ha llamado democracia delegativa ${ }^{5}$ que correspondería a un tipo de débil funcionamiento democrático. Por el contrario, el caso chileno presenta enclaves autoritarios heredados tanto de la dictadura como de los amarres o acuerdos de transición, que limitan el carácter democrático, es decir, de expresión de la soberanía popular o, en la definición del Proyecto RIDA, las capacidades ciudadanas para el autogobierno propio de las democracias fuertes. Estos enclaves son de dos tipos, institucionales y actorales, y estos últimos constituyen lo que puede denominarse poderes fácticos, los que pueden ser fácticos puros (medios de comunicación, por ejemplo) o "de jure" (tribunal constitucional, por ejemplo).

Sin duda, esta hipótesis u orientación básica entra en contradicción con el sentido común generalizado en la opinión pública de la región y difundido por múltiples informes y rankings internacionales que ubican en un lugar privilegiado de los índices democráticos a Chile. Ello porque estamos frente a una paradoja básica, esto es, existe una contradicción entre esta democracia incompleta y el desempeño de los gobiernos con respecto al crecimiento económico, la superación de la pobreza y la inserción en la economía global, por nombrar sólo algunas variables (aunque los niveles de desigualdad se mantienen relativamente constantes, con muy leve mejoramiento en los últimos años gracias a la focalización de subsidios y gasto social). No se puede evaluar el estado de la democracia en Chile sin analizar esta tensión característica de la democracia en Chile: por un lado, la herencia de un marco institucional y socioeconómico que da lugar a los aspectos deficitarios de la democracia y de su desempeño y, por otro, la existencia

3 Ver M.A. Garretón. 2003, Incomplete Democracy. Political Democratization in Chile and Latin America. Chapel Hill: University of North Carolina Press.

4 Extrapolando a un caso democrático el concepto de Juan Linz de "situación" (diferenciándolo del concepto de régimen) para referirse al caso autoritario de Brasil. Ver J. Linz. 1973, "The Future of an Authoritarian Situation or the Institutionalization of an Authoritarian Regime: Brazil", in Alfred Stepan ed., Authoritarian Brazil: Origins, Politics, and Future, New Haven, Yale University Press, pp. 232-254.

5 O'Donnell, G. 1977, Contrapuntos. Ensayos escogidos sobre autoritarismo y democratización. Buenos Aires: Paidós. 
inédita de una sólida coalición política, la Concertación de Partidos por la Democracia, que explicaría sobre todo los aspectos positivos.

\section{DEMOCRACIA CONSTITUCIONAL}

\section{a. La cuestión de fondo}

No es posible hacer un análisis de las cuestiones planteadas sin asumir la profunda división que hay en la sociedad chilena respecto de la Constitución: no hay real consenso sobre su legitimidad de origen, su contenido ni sobre si representa o no la voluntad del pueblo chileno. Se trata del único caso en el mundo de una Constitución adoptada bajo una dictadura militar que sigue vigente en un régimen democrático.

Impuesta por la dictadura militar a través de un plebiscito fraudulento, esa Constitución, modificada en algunos aspectos por los acuerdos entre la dictadura y la oposición entre el plebiscito de 1988 y las elecciones presidenciales de 1990 por un nuevo plebiscito, esta vez correcto, en julio de 1989, buscó asegurar su perennidad e inmutabilidad a través de cinco mecanismos-enclaves: 1 . La incorporación al Senado de miembros nominados al margen de elecciones populares: senadores elegidos por la Corte Suprema, el Presidente de la República, el Consejo de Seguridad Nacional. 2. La incorporación al Senado de los ex Presidentes de la República (sin distinción de si fueron o no elegidos democráticamente, exigencia que contiene la actual Constitución de Paraguay y la anterior de Venezuela). ${ }^{6}$ 3. Altísimos quórum para modificar la Constitución Política ( $2 / 3$ de sus disposiciones más importantes y $3 / 5$ para el resto). 4 . Un sistema electoral minoritario (aunque presentado como mayoritario) binominal, en el que, salvo en el caso de que una de las combinaciones políticas doble a la segunda mayoría (o primera minoría), se produce un empate en el $90 \%$ de los distritos, y en prácticamente todas las circunscripciones electorales. 5. La calificación que la Constitución hace, para una gran cantidad de materias, entre leyes normales, leyes de quórum calificado y leyes orgánicas constitucionales, exigiendo para estas dos últimas materias quórum superiores a la mayoría simple: $4 / 7$ de los diputados y senadores en ejercicio. Son leyes orgánicas constitucionales, entre otras, las leyes electoral, sobre educación pública, partidos políticos, minas, administración pública, estados de excepción, Congreso Nacional, organización y atribuciones de los tribunales, Ministerio Público, Tribunal Constitucional, Tribunal Calificador de Elecciones, Contraloría General de la República, Fuerzas Armadas y Carabineros (Policía Uniformada), Banco Central, división política y administrativa del territorio, consejos regionales y provinciales, administración municipal. Las leyes de quórum calificado requieren de la mayoría absoluta de los parlamentarios en ejercicio, y son, entre otras, la que describe las conductas terroristas, la que determina los delitos susceptibles de ser castigados con la pena de muerte (aunque ésta ha sido muy limitada), la que protege la honra de las personas de los abusos de la libertad de expresión, Consejo Nacional

6 La Comisión Interamericana de Derechos Humanos, en informe de enero de 2000, resolvió que esta composición del Senado vulneraba el derecho humano de los ciudadanos chilenos a la igualdad del voto (Caso $\mathrm{N}^{\circ} 11.863$, Informe 137/99). 
de Televisión, la regulación del derecho a la seguridad social, la que autoriza al Estado a realizar actividades empresariales, así como la que exime al Estado en estos casos de la legislación común, las que protegen el derecho de propiedad de los particulares; las que autoricen al Estado y sus órganos a contratar créditos que excedan el tiempo del mandato presidencial; indultos generales y amnistías (aunque para concederlos para delitos de carácter terrorista, el quórum será de 2/3). Además, las leyes que interpreten preceptos constitucionales requieren del voto de $3 / 5$ en cada Cámara. Incluso los tratados internacionales, si inciden en materias que deben ser objeto de leyes orgánicas constitucionales o de quórum calificado, no podrán ser ratificados si no se reúnen los quórum necesarios para adoptar o modificar estas últimas.

Si bien los dos primeros mecanismos-enclaves fueron derogados por la reforma del 2005 bajo el Presidente Lagos -ya habían perdido importancia para los partidos ligados a la dictadura-, los otros siguen en pleno vigor, provocando una fuerte distorsión de la voluntad popular en el Parlamento, por una parte, y una exclusión de los sectores ajenos a las dos fuerzas mayoritarias. ${ }^{7}$ Ejemplos de esta distorsión son la imposibilidad de modificar el sistema binominal; el no otorgamiento de voto a los chilenos que viven en el extranjero (una gran mayoría de ellos expulsados por la dictadura o refugiados por ella); modificar todas las leyes que sobre materias propias de leyes orgánicas constitucionales o de quórum calificado adoptó Pinochet y su junta legislativa en los últimos días de dejar el poder.

La mayor cantidad de conflictos sociales producidos en los últimos años tienen por causa la imposibilidad de obtener los quórum necesarios, sea para modificar la Constitución o para modificar las leyes de quórum especiales. Muchas otras iniciativas legales no han logrado prosperar por la imposibilidad de obtener los quórum requeridos e incluso tratados internacionales, en especial desde la detención de Pinochet en Londres, como lo veremos más adelante. Así, el Tribunal Constitucional, a requerimiento de parlamentarios de la oposición de derecha, resolvió que el Estado de Chile no podía ratificar el Estatuto de la Corte Penal Internacional -en cuya elaboración la delegación de Chile había tenido una activa participación- sin una modificación constitucional, a la que siempre se han opuesto. Iniciativas que concitaban gran apoyo ciudadano fueron rechazadas o modificadas en tal forma que el proyecto aprobado resultó irreconocible para sus autores. Recientemente, parlamentarios de ese mismo sector exigieron -para aprobar la ratificación del Convenio 169 de la Organización Internacional del Trabajo sobre Pueblos Indígenas y Tribales en Países Independientes- una reserva (aunque el Convenio no admite reservas) o una Declaración (que la OIT no aceptó) las que perseguían quitarle al Convenio gran parte de sus finalidades. Finalmente, la Presidenta decidió depositar el instrumento de ratificación en la OIT el 15 de septiembre de 2008 sin declaración alguna, con lo que sólo después de 18 años Chile dejó de ser el único país latinoamericano que no era parte del instrumento más significativo para los pueblos indígenas.

7 Sólo en la elección parlamentaria de diciembre del 2009 un sector ajeno a una de las dos listas principales obtuvo algunos escaños, en tanto el Partido Comunista tuvo que hacer un pacto con la lista de la Concertación para elegir parlamentarios como parte de dicha lista. 
El núcleo básico de la Constitución, un marco de hierro incambiable y perenne para un determinado orden socioeconómico, no pudo ser modificado por las reformas constitucionales de 2005 bajo el gobierno de Lagos. Si bien los senadores nominados $\mathrm{y}$ vitalicios fueron eliminados al igual que el papel tutelar de las fuerzas armadas a través del Consejo de Seguridad Nacional y otros aspectos fueron también derogados, este núcleo permaneció inalterable. La reforma no se pronunció sobre el sistema de elección binominal, si bien le restó el rango constitucional, pasando a estar regulado por una ley de quórum calificado. ${ }^{8}$ Lo grave es que al cambiársele la firma de Pinochet por la de Lagos y al proclamar el Presidente que se trataba de una nueva Constitución se clausuró el debate constitucional sin que el pueblo chileno haya tenido un verdadero "momento constitucional".

En este contexto, si no se tiene en cuenta que en Chile hay una estructura jurídica destinada a saltarse la voluntad y soberanía populares, las respuestas a las cuestiones planteadas por el marco metodológico del Proyecto RIDA que incluimos a continuación pueden inducir a errores muy graves de apreciación. El análisis de la situación chilena debe enfocarse en una perspectiva de derechos humanos, de manera que tome en cuenta que, tras el fin de la dictadura, el pueblo chileno sólo recuperó de manera parcial el derecho a su libre determinación, consagrado en el único artículo común a los pactos de derechos económicos, sociales y culturales y de derechos civiles y políticos adoptados por las Naciones Unidas en 1966. Del mismo modo que se afirma que no basta que haya elecciones para que exista democracia, tampoco basta que los poderes del Estado funcionen regularmente y se adopten leyes por consenso, para que exista un consenso social real sobre la naturaleza del régimen constitucional en vigor. Cabe recordar que la oposición a la dictadura de Pinochet tuvo como uno de sus objetivos fundamentales adoptar una Constitución que reemplazara por completo la impuesta por aquél.

\section{b. Independencia de los poderes Ejecutivo y Legislativo}

El siguiente es el estado de situación para los diversos puntos contemplados en el marco metodológico del Proyecto RIDA en esta materia.

- La Constitución da mucho poder al Ejecutivo en materia legislativa, como es, por ejemplo, la iniciativa exclusiva en materias que requieren financiamiento estatal o el mecanismo de las urgencias. Sin embargo, el Ejecutivo no ha ejercido su capacidad legislativa contra la voluntad del Congreso. Sólo hay un caso en que ejerció una atribución legal, al rechazar el Parlamento un proyecto de ley destinado a aportar fondos para solucionar un problema de transporte público colapsado. Conforme al artículo 32 numeral 22 de la Constitución, el Ejecutivo estimó que se produciría una calamidad pública y -sin ley-autorizó el uso de fondos públicos previstos para

8 La reforma de 2005 tuvo otras consecuencias importantes, como la eliminación del requisito de un año de residencia en Chile -que contenía el texto original- para que los hijos de chilenos nacidos en el extranjero accedan a la nacionalidad chilena. Pero no podrán ejercer su ciudadanía sino luego de un año de avecindarse en Chile. Además limita aun más atribuciones de un Consejo de Seguridad Nacional creado por la dictadura, lo que ya se había hecho en 1989. 
estos casos, hasta el $2 \%$ del monto de los gastos autorizados por el presupuesto de la Nación

- Las leyes que discute el Parlamento son de interés público, local, regional, sectorial o nacional, si bien hay algunos parlamentarios que defienden intereses particulares de algunos sectores afines. Rara vez esos intereses se traducen en leyes. Aunque a comienzos de la transición hubo una denuncia -que resultó infundada- de tráfico de drogas, el tema no es un problema en la política chilena.

- En general, los procesos legislativos son transparentes. Es verdad que hay materias que se legislan en sesiones secretas y en los comienzos del régimen democrático se adoptaron algunas leyes secretas, con acuerdo de todas las fuerzas políticas. Las sesiones plenarias y algunas de comisiones son transmitidas por los canales de televisión de ambas Cámaras. Una de las pocas leyes con nombre propio fue el precio de pagar el retorno de Pinochet desde España, pero perdiendo el cargo de Senador Vitalicio que ostentaba. Se hizo una reforma constitucional para suprimir la pertenencia al Senado de los ex Presidentes (con lo cual los sectores de la oposición ligada al dictador lograron que los presidentes elegidos popularmente tampoco fuesen senadores), a cambio de pensiones y honores.

- No se presiona a las otras ramas para el cumplimiento de las leyes, sin perjuicio de lo que se dirá más adelante.

- El Ejecutivo cumple las leyes adoptadas por el Congreso. Salvo los casos de una Ministra de Estado y un senador que se mencionarán más adelante, no hay constancia de que algún órgano del Estado haya destituido a un miembro de otro poder del Estado, desde el retorno a la democracia en 1990. El Ejecutivo sanciona a sus funcionarios que han cometido abusos y, si se trata de delitos, la sanción penal la aplican los jueces. El Congreso no tiene facultades para sancionar a los parlamentarios y si éstos incurrieren en causales de inhabilidad pueden ser destituidos por el Tribunal Constitucional. Además de estas incompatibilidades razonables, la Constitución vigente agregó estas otras, difícilmente compatibles con estándares democráticos: intervención en negociaciones laborales; intervención "en actividades estudiantiles, cualquiera que sea la rama de la enseñanza, con el objeto de atentar contra su normal desenvolvimiento; o incitación a la alteración del orden público, o propicie el cambio del orden jurídico institucional por medios distintos a los que establece esta Constitución", o "comprometer gravemente las seguridad o el honor de la Nación", conductas que también pueden originar la destitución por el Tribunal Constitucional (artículo 82, N 11 de la Constitución). Desde la restitución democrática, esta facultad la ejerció una vez la bancada de diputados de oposición pero fue desestimada por el Tribunal Constitucional.

- El Congreso puede, mediante el procedimiento de acusación constitucional (acusación aprobada por la Cámara de Diputados, que es sometida al Senado para que resuelva como jurado), destituir al Presidente de la República (requiere 2/3 de los miembros en ejercicio); a los Ministros de Estado, magistrados de los tribunales superiores de justicia (jueces de las cortes de apelaciones y Suprema), Contralor General de la República, generales y almirantes, intendentes y gobernadores por la mayoría 
de sus miembros en ejercicio (artículos 52 y 53 de la CPE). Así, en 1993 el Senado hizo una acusación constitucional por notable abandono de funciones deducida en contra de un integrante de la Corte Suprema, el que quedó destituido. En abril de 2008 el Senado destituyó a una Ministra de Estado mediante cargos imprecisos, asunto que al momento de terminar este informe se encuentra en conocimiento de la Comisión Interamericana de Derechos Humanos. Lo grave es que conforme a la Constitución, el o la Ministro destituido, aunque no hubiere cometido ninguna falta penal, queda inhabilitado por cinco años para ejercer cargos u oficios públicos. Por último, un senador fue cesado en su cargo, pero por consecuencia de una sentencia pronunciada por un tribunal del crimen, que lo condenó a cinco años de presidio por el delito de abusos sexuales a menores.

- No hay casos en que a funcionarios elegidos les haya sido impedido asumir o servir el cargo. Sólo está el caso del senador condenado, y, además, el de uno asesinado. En ambos casos operó el sistema previsto en la Constitución para la suplencia. Dos de los titulares de cargos públicos han terminado sus mandatos, sin interferencia de otras ramas, salvo las excepciones mencionadas, que se han producido como consecuencia de procedimientos democráticos.

- No existe corrupción generalizada en los cargos ejecutivos y legislativos ni en la administración del Estado: los casos puntuales han sido denunciados por las autoridades y entregados a la Contraloría y/o a la justicia. La mayor cantidad de estas situaciones se ha dado a nivel de los municipios. La Contraloría General de la República ejerce sus funciones con independencia y rigor. La Ley de Transparencia de la Función Pública y Acceso a la Información de los Órganos de Administración del Estado entró en vigencia en abril de 2009 con la creación de un Consejo para la Transparencia y ya ha provocado un gran impacto en la medida que permite la participación y control de cualquier ciudadano sobre actos del Estado, en especial sus aspectos económicos. ${ }^{9}$

\section{c. Independencia del Poder Judicial}

Desde el mismo momento del golpe militar del 11 de septiembre de 1973, el Poder Judicial, que lo apoyó explícitamente, se transformó en una instancia subordinada a la dictadura militar, obedeciendo todos sus dictámenes y obteniendo por ello una gran compensación a través de un alza desmedida de sus remuneraciones y otras granjerías. Se trató de un poder judicial corrupto, aunque hubo jueces que fueron claras excepciones, por lo que en general fueron reprimidos o castigados por sus propios pares. Ello significó la casi absoluta desprotección de los derechos humanos violados por la dictadura

A la vuelta a la democracia, al conocerse el informe de la Comisión Nacional de Verdad y Reconciliación que estableció de manera oficial la verdad sobre las violaciones de los derechos humanos cometidas por la dictadura y criticó duramente la actuación del Poder

9 Ver S. Zamorano, “Ley de Acceso a la Información. El nuevo poder ciudadano”. Revista Mensaje, Santiago, marzo-abril 2009. No 577. 
Judicial, la Corte Suprema descalificó dicho Informe. De hecho, en los primeros ocho años de la transición las cortes se mantuvieron en las mismas posturas antidemocráticas, reconociendo como legítimas todas las actuaciones de la dictadura, traspasando las causas en que tenían interés los militares a los tribunales militares y consagrando la impunidad de todos los ilícitos -incluidos crímenes contra la humanidad-de sus responsables. ${ }^{10}$ La Justicia Militar reclamó para sí todos los procesos concernientes a violaciones de los derechos humanos y las contiendas de competencia siguieron siendo resueltas por la Corte Suprema en su favor, sede donde las causas se terminaban por falta de pruebas o por la declaración de sobreseimiento en virtud del decreto de ley de amnistía, que a su turno era confirmada por la Corte Marcial y finalmente por la Corte Suprema. También, durante los primeros ocho años de la transición, los tribunales castrenses -impedidos ahora de juzgar a civiles por el delito de ofensa a las Fuerzas Armadas o a Carabinerosdecidieron procesar a dirigentes políticos, periodistas y abogados de derechos humanos por declaraciones $\mathrm{u}$ opiniones que cuestionaban las atrocidades de la dictadura por el delito de sedición impropia pasible de una pena de 61 días a cinco años de privación de libertad, abuso que fue legitimado por la Corte Suprema.

El cambio en la actuación de los jueces se produjo el 16 de octubre de 1998 con la detención de Pinochet en Londres a petición de la justicia española. El "efecto Garzón" (del nombre del juez español que hizo detener a Pinochet) significó que los jueces chilenos, deseosos de recuperar el crédito perdido por su obsecuencia ante la dictadura, comenzaron a retener para sí las causas reclamadas por la Justicia Militar; a encausar a militares comprometidos en crímenes de lesa humanidad y a proveer argumentos para no aplicar la ley de autoamnistía de 1978, alzando la inmunidad de Pinochet y procesándolo. La mayor parte de los jueces de la Corte Suprema y demás jueces, aunque no todos, hoy aplican el derecho internacional tanto convencional como consuetudinario y condenan a los responsables. No obstante, las penas que se aplican no guardan relación con la gravedad de los crímenes cometidos, por lo que se cumplen rápidamente y en muchos casos se cumplen en libertad.

Hoy puede decirse que el Poder Judicial es independiente, en especial en materia de derechos humanos, campo en el que se han producido avances notables. En el 2008 existían 345 procesos abiertos en los que se investigan las situaciones de 1.138 víctimas ejecutadas o desaparecidas. Se han dictado autos de procesamiento en contra de 686 militares y policías, incluyendo 39 generales o almirantes; 85 agentes están condenados por sentencia firme de último grado y algunos en varias causas. ${ }^{11}$

10 El texto original de la Constitución de 1980 sólo declaraba que "el ejercicio de la soberanía reconoce como limitación el respeto de los derechos esenciales que emanan de la naturaleza humana". La reforma constitucional pactada luego del referéndum que puso término a las aspiraciones de perpetuidad de Pinochet, entre sus seguidores y los partidos democráticos, incorporó explícitamente a la Constitución los tratados de derechos humanos, disponiendo en su nuevo inciso segundo del artículo 5 que "El ejercicio de la soberanía reconoce como limitación el respeto a los derechos esenciales que emanan de la naturaleza humana. Es deber de los órganos del Estado respetar y promover tales derechos, garantizados por esta Constitución, así como por los tratados internacionales ratificados por Chile y que se encuentren vigentes".

11 Por ejemplo, el ex Director de la Dirección de Inteligencia Nacional (DINA) acumula ya condenas en numerosas causas por 57 años y se espera confirmación en otras 15 en las que ha sido condenado, en primera o segunda 
Además, por un lado, los jueces actuales han sido implacables en la persecución de la corrupción y son muchas las veces que los jueces han impedido acciones del Ejecutivo, en especial acogiendo recursos de protección de las garantías constitucionales.

En 2000 comenzó a implementarse de forma gradual la reforma procesal penal sustituyendo el anacrónico sistema escrito e inquisitivo por el oral y acusatorio, a la que han seguido reformas integrales a la justicia de familia y laboral, y se estudia una reforma para la justicia civil. Las reformas hicieron de hecho que el presupuesto anual del Poder Judicial se haya triplicado en términos reales. Aun así, la mayor demanda de justicia -sobre todo en el ámbito de la justicia de familia- hizo que los cuantiosos nuevos fondos fuesen insuficientes. ${ }^{12}$

A pesar de estos progresos hay todavía importantes déficits. Uno de ellos es la subsistencia de la competencia de la Justicia Militar tanto para juzgar delitos cometidos por civiles como respecto de delitos cometidos por militares contra víctimas civiles. En cuanto a lo primero, esta competencia ya había sido muy limitada por leyes adoptadas en el primer año del régimen democrático y hoy está limitada a los delitos de agresiones de hecho en contra de militares y carabineros. Con esa reforma y otras posteriores, los jueces militares dejaron de juzgar delitos de ofensas verbales o por escrito a las fuerzas armadas, carabineros, a sus órganos o miembros; los delitos contemplados en la ley que describe los delitos de terrorismo, y varios contemplados en la ley de control de armas y explosivos. Sin embargo, sus competencias para juzgar delitos cometidos por militares y carabineros contra civiles no fueron modificadas. Esta anomalía queda de manifiesto en las demandas de tierras del pueblo mapuche, cuando se producen enfrentamientos en los que son heridos carabineros y los mapuches detenidos son torturados: el tribunal castrense juzga tanto los ataques que causaren muerte o lesiones a carabineros (artículos 416 y 416 bis del Código de Justicia Militar) como las torturas (llamadas "violencias innecesarias") que éstos cometen, quedando en evidencia un doble estándar en cuanto a la imparcialidad e independencia del órgano judicial y del juicio mismo. De hecho, en los dos casos de muertes producidas durante incidentes reivindicatorios de tierras por grupos mapuches, los muertos han sido manifestantes civiles mapuches, muertos por carabineros. ${ }^{13}$

El segundo déficit lo constituye el que no se aprovechó la exitosa reforma procesal penal para asumir diversas manifestaciones del derecho consuetudinario indígena como ocurrió en otros países. Algunas mejoras que surgieron de la reforma incluyen la exigencia de intérpretes durante el juicio, así como la creación de una Defensoría Mapuche, la que ha demostrado una gran debilidad. La reforma ha beneficiado a los mapuches en los procesos comunes de los que son acusados, mas no así en los procesos relacionados con

instancia, a un total de 197 años de privación de libertad. Ello sin perjuicio de la condena ya cumplida de 7 años por el crimen de Orlando Letelier en Washington.

12 El presupuesto judicial ha sido siempre deficitario en Chile y, además, es administrado por el Ejecutivo. En la práctica el margen de intervención del Poder Judicial es muy limitado. El Poder Judicial ha reclamado con frecuencia su voluntad de administrar por sí mismo el presupuesto que le corresponde.

13 Alex Lemún en 2002 y Matías Catrileo, en 2008; en ambos casos los autores de los disparos están identificados y también en ambos casos no han sido aún condenados. 
sus reivindicaciones históricas. La demanda de tierras es enfrentada con la legislación penal aplicable a cualquier persona y, peor aún, con la legislación antiterrorista de la época de la dictadura que, si bien fue modificada de manera significativa, mantiene sus características represivas. Incluso, las condenas penales no pueden ser-como ya se explicó- objeto de indultos o amnistías regulares dado el quórum especial exigido por la Constitución para estos delitos. Tanto la Oficina del Alto Comisionado de las Naciones Unidas para los Derechos Humanos para América Latina y el Caribe como el Relator Especial sobre los derechos de los indígenas han repudiado este abuso en la aplicación de la ley antiterrorista.

Respecto de las relaciones con otros poderes, no hay usurpación o invasión de las atribuciones judiciales por parte de los poderes Legislativo ni Ejecutivo. Tampoco ha habido remociones ni interferencia en el nombramiento de los magistrados. Los jueces desde el primer grado hasta el de juez de cortes de apelaciones eran nombrados mediante un procedimiento que rigió desde hace más de 80 años. Luego de una reforma constitucional de 1997 los jueces (ministros) de la Corte Suprema son nombrados por el Ejecutivo a partir de listas de postulantes elaboradas por la misma Corte, debiendo ser la mitad de los jueces provenientes de la carrera judicial y la otra de abogados ajenos a ella. El sistema fue exitoso porque permitió remover a los jueces nombrados en las postrimerías del régimen militar y que impedían todo progreso en la administración de justicia, en particular con respecto a crímenes contra la humanidad. Pero la reforma terminó como triunfo de los sectores ligados al antiguo régimen: desde ese momento en el nombramiento interviene -además del Poder Judicial (mediante la lista confeccionada por la propia Corte Suprema) y del Poder Ejecutivo (que seleccionaba a uno de los incluidos en la lista)-el Poder Legislativo, pues el nombramiento del Ejecutivo debe ser aprobado por los 2/3 del Senado. El resultado es que para cada nueva vacante, se turna el nuevo juez, uno para un juez de carrera o abogado externo de simpatía para el Gobierno, el siguiente, para la oposición. Se trata de un empate que reproduce el empate político consagrado por el sistema binominal y que resulta ser el núcleo duro del sistema institucional heredado que mantiene el carácter limitado e incompleto de la democracia. ${ }^{14}$

\section{d. Tribunal Constitucional}

El Tribunal Constitucional tiene entre sus funciones ejercer el control de las leyes emanadas del Poder Legislativo. En los casos de las leyes orgánicas constitucionales, interpretativas de la Constitución y de ratificación de tratados relativos a materias propias de la Constitución, el control es preventivo, antes de su promulgación. Respecto de leyes ordinarias lo puede hacer a instancia de parte (artículo 93, Nos. 1, 6 y 7). Además, el Tribunal se pronuncia sobre la constitucionalidad de actos propiamente gubernativos, como son los decretos supremos, si previamente la Contraloría General de la República 
(otro órgano no dependiente del Ejecutivo) hubiese considerado que no se ajusta a la Constitución. Además de estas atribuciones que resuelven conflictos entre órganos del Estado, los tribunales ordinarios (jueces civiles, laborales, del crimen, de familia, cortes de apelaciones y Suprema) permanentemente cuestionan los actos jurídicos del Ejecutivo. No hay "leyes del Gobierno" pues las leyes son del Legislativo. En un caso que causó gran revuelo, un decreto del Ejecutivo dispuso distribuir gratuitamente a las mujeres violadas o que corriesen el riesgo de un embarazo no deseado la llamada píldora del día después. En abril de 2008 el Tribunal Constitucional, acogiendo un requerimiento de parlamentarios de extrema derecha, estimó que la píldora era abortiva y, por lo tanto, contraria a la protección del derecho a la vida que consagra la Constitución, y dispuso que el decreto del Ejecutivo no se cumpliese. En este sentido, es evidente que el Tribunal Constitucional pasó a ser un poder fáctico, que decide sobre cuestiones que van mucho más allá de su competencia y al que recurre la oposición de derecha cuando es derrotada en el Parlamento. No obstante, en enero de 2010, el Tribunal no objetó la constitucionalidad de un proyecto de ley enviado por el Ejecutivo que legalizaba el reparto de la píldora.

\section{e. Predominio civil sobre militares y estados de excepción}

La transición a la democracia en Chile dio por resultado, como hemos dicho, una democracia limitada o incompleta, que implicaba que no habría completa justicia por las violaciones de los derechos humanos cometidas durante la dictadura y que habría un poder de veto de los militares sobre una serie de materias a través no sólo del control en el Parlamento gracias al sistema binominal y los senadores designados, sino del Consejo de Seguridad Nacional, el Tribunal Constitucional, gastos reservados, etc.

Traspasado el mando al Presidente civil elegido y perdidas sus principales atribuciones, los militares procuraron ejercer al máximo su poder, aprovechando un elemento que marcó la transición chilena: Pinochet, si bien dejó de ser Presidente, continuó como primera autoridad del Ejército por los siguientes ocho años. En 1998, Pinochet tuvo que entregar la Comandancia en Jefe del Ejército, quedando por primera vez como un civil más, aunque asumió el puesto de Senador vitalicio por su calidad de ex Presidente de la República. Como hemos indicado, a fines del mismo año Pinochet fue detenido en Londres por demanda de jueces españoles. El desconcierto y el fracaso político en solucionar el problema llevaron al gobierno a crear en 1999 una mesa de diálogo para por fin cerrar el tema de los derechos humanos y sus violaciones durante la dictadura. El citado "efecto Garzón" también llegó a las Fuerzas Armadas, que en el documento de la mesa reconocieron su participación en la violación de derechos humanos. En 2003, el Comandante en Jefe, el General Cheyre, anunciaba un "nunca más" y renunciaba a la doctrina de seguridad nacional como doctrina del Ejército. Los ascensos a general se restringieron a quienes no hubieran participado en violaciones de derechos humanos. Los militares volvieron a sus funciones profesionales. Sólo después de trece años de recuperada la democracia, las Fuerzas Armadas dejaban de ser un poder fáctico. Hoy la dictadura es defendida con mucha más fuerza y vehemencia por sus componentes civiles que por los militares. 
Respecto de algunas cuestiones particulares en el campo de las relaciones civiles-militares, no se advierten interferencias de militares y policías en la selección ni en el ejercicio de las atribuciones de presidentes, diputados, senadores, alcaldes y concejales, únicos cargos de elección popular en Chile. Hoy las Fuerzas Armadas y sus miembros aceptan el Estado de derecho y la Constitución, a tal punto que los militares que están siendo juzgados y condenados por las violaciones de los derechos humanos cometidos durante la dictadura se sienten abandonados por los actuales oficiales militares.

Las autoridades elegidas ejercen sus funciones sin influencias ilegítimas de las fuerzas militares, en términos efectivos a partir del año 2003, en que el Comandante en Jefe anunció el abandono del Ejército de la doctrina de seguridad nacional.

Desde el día que asumió el primer Presidente civil una vez derrotada la dictadura, no se ha declarado ningún estado de excepción, siendo un hecho sin precedentes en la historia de Chile los diecinueve años sin que las autoridades recurran a esta medida. Por otra parte, la reglamentación represiva de los estados de excepción fue morigerada primero en 1989 y luego en 2005. Se estableció como garantía de los derechos susceptibles de ser afectados en los estados de excepción que "respecto de las medidas particulares que afecten derechos constitucionales, siempre existirá la garantía de recurrir ante las autoridades judiciales a través de los recursos que corresponda". Esta norma viene a subsanar la aberrante jurisprudencia que sostenía que en los estados de excepción no procedía el habeas corpus.

\section{f. Libertad de expresión}

Sin perjuicio de retomar este tema más adelante, es útil afirmar aquí que la prensa cubre los procesos electorales con absoluta libertad, si bien sin ninguna profundidad. Además, en los últimos 30 días previos a las elecciones de Presidente de la República, de diputados y de senadores, los canales de televisión, según la ley, "deberán destinar gratuitamente treinta minutos diarios de sus transmisiones a propaganda electoral" en condiciones de igualdad de tiempo para las presidenciales y proporcionales a los resultados de la última elección para las parlamentarias. No existe esta obligación en las elecciones municipales. No hay verdaderos debates, pero ello no se debe a políticas oficiales sino a opciones de los medios que responden casi todos a una misma orientación ideológica. El periodismo investigativo, que tuvo un amplio desarrollo durante la dictadura, ha tenido algunas trabas que provienen de los mismos medios.

\section{DEMOCRACIA ELECTORAL}

La cuestión básica que está detrás de este tema tiene que ver con nuestra hipótesis central de democracia incompleta o limitada. Así, el acceso al derecho a voto, la limpieza de los procedimientos y las alternativas de que dispone el elector han logrado importantes progresos tras las reformas posteriores al fin de la dictadura y ubican a Chile en buena posición comparativa. Sin embargo, existen serios déficits democráticos en este campo. 
En primer lugar, no todas las alternativas de que dispone el elector tienen la posibilidad de estar representadas en los cuerpos colegiados (ambas ramas del Parlamento y concejos municipales) en proporción al número de adherentes de cada corriente política. La comprobación preliminar de que ello no es así en Chile lo demuestra que el ciento por ciento de los parlamentarios elegidos desde la restitución democrática hasta las elecciones de 2009 (el progreso en esta última fue marginal y el principal partido fuera de los bloques se vio obligado a participar en la lista de uno de éstos para lograr elegir tres diputados) han pertenecido a dos coaliciones de partidos que debaten entre sí y se distribuyen los cargos parlamentarios, marginando a las demás fuerzas.

Este punto refiere a la cuestión crucial del sistema electoral binominal mayoritario heredado de la dictadura, que favorece el empate político entre mayoría de gobierno y minoría opositora mientras excluye otras opciones. La oposición de derecha a la Concertación (la coalición gobernante) se ha negado a modificar este sistema, no sin cierta complicidad de algunos sectores de esta última. ${ }^{15} \mathrm{El}$ binominalismo se puede sintetizar señalando que sólo acepta dos puestos por cada circunscripción o distrito y que una lista de candidatos (normalmente constituida por alguna coalición de partidos) para obtener los dos puestos debe doblar a la otra lista. En teoría, esto significa que si hay dos listas, la minoritaria, con un $34 \%$ de votos obtiene la mitad de los escaños. Una ilustración clara la entregan los siguientes cuadros teóricos:

Lo anterior ha tenido cuatro implicancias fundamentales: a) Le da un poder de veto a la minoría, más aún cuando, como hemos indicado más arriba, la legislación más significativa exige un quórum imposible de alcanzar por una de las dos listas. Al tratarse de una minoría ligada al régimen militar, su función ha sido preservar los elementos no democráticos de la institucionalidad heredada. b) Excluye una tercera fuerza. En efecto las fuerzas de izquierda fuera de la Concertación que alcanzan porcentajes cercanos al $12 \%$ a nivel nacional no tienen representación parlamentaria. c) Asegura prácticamente la reelección permanente de los incumbentes y no permite las alternativas dentro de los bloques y/o partidos al limitar el número de candidatos. d) Reemplaza la competencia entre las diversas fuerzas por la competencia al interior de los bloques.

Se trata de un sistema que difícilmente puede pasar un test democrático, en el sentido de que distorsiona la voluntad popular y el principio de representación. Esta distorsión tiene a su vez efectos perniciosos sobre la calidad de la democracia, ya que al ser tan fácil predecir quiénes serán los diputados y senadores electos en los distritos y circunscripciones (salvo un puñado de excepciones), repercute en una alta desafección, baja participación y competencia. El resultado es la generación de un empate político entre las fuerzas que apoyaron la dictadura y las que se opusieron a ella, haciendo imposible un cambio significativo en la institucionalidad heredada de la dictadura. ${ }^{16}$

15 La Constitución Política de 1980 entrega la regulación del sistema electoral a una ley orgánica constitucional, materias hoy reguladas por la Ley $\mathrm{N}^{\circ} 18.556$ sobre sistema de inscripciones electorales y servicio electoral de 1986, y por la Ley N $\mathrm{N}^{\mathrm{0}} 18.700$ sobre votaciones populares y escrutinios, dictada por la Junta Militar en 1988. Esta última ley rige la elección del Senado y de la Cámara de Diputados de la República, además de la de Presidente de la República.

16 Pese a lo indiscutible de la distorsión de la voluntad ciudadana que provoca este sistema binominal (ver C. Huneeus (comp.), "La reforma del sistema binominal en Chile. Una contribución al debate”. Konrad 
Cuadro 1: Resultados teóricos del sistema binominal

Elección con dos partidos (o bloques), con resultado empate:

\begin{tabular}{cccc}
\hline Lista A & Elige & Lista B & Elige \\
\hline $66 \%$ & 1 dip. & $34 \%$ & 1 dip. \\
\hline
\end{tabular}

Elección con dos partidos (o bloques), mayoría dobla a minoría:

\begin{tabular}{cccc}
\hline Lista A & Elige & Lista B & Elige \\
\hline $67 \%$ & 2 dip. & $33 \%$ & 0 dip. \\
\hline
\end{tabular}

Elección con pluralidad de partidos (o bloques), con resultado empate:

Lista A Elige Lista B Elige Lista C Elige Lista D Elige Lista E Elige Lista F Elige

\begin{tabular}{llllllllllll}
$30 \%$ & 1 dip. & $16 \%$ & 1 dip. & $15 \%$ & 0 dip. & $14 \%$ & 0 dip. & $13 \%$ & 0 dip. & $12 \%$ & 0 dip. \\
\hline
\end{tabular}

Elección con pluralidad de partidos (o bloques), primera mayoría dobla a segunda:

Lista A Elige Lista B Elige Lista C Elige Lista D Elige Lista E Elige Lista F Elige

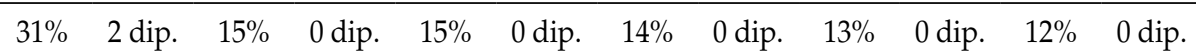

En segundo lugar, este empate político consagrado por el sistema electoral se reproduce a través de diversas instituciones cuyos miembros son propuestos o decididos por el Senado (jueces de la Corte Suprema y del Tribunal Constitucional, Banco Central, televisión pública, educación, etc.) y cuya normativa orgánica no puede ser cambiada debido a los altos quórum que exige su modificación, los que no pueden ser alcanzados debido al sistema electoral.

En tercer lugar, el sistema electoral tiene efectos en la dimensión constitucional y en la democracia ciudadana. La profundización de la democracia en sus aspectos de igualdad socioeconómica, base indispensable de una verdadera igualdad político-ciudadana, ha sido impedida por la oposición de derecha identificada con el modelo socioeconómico heredado. Así, la minoría electoral gracias al poder de veto que le da el sistema binominal y las disposiciones constitucionales ha logrado impedir que se transformen en leyes, demandas emblemáticas y prioritarias que inciden en la democracia constitucional y ciudadana, como, por ejemplo, la modificación del sistema minoritario binominal y su sustitución por uno proporcional; el otorgamiento de voto a los chilenos que viven en el extranjero, gran parte ellos expulsados por la dictadura o refugiados a causa de ella; una adecuada reforma educacional y apoyo a la educación pública; el cobro de royalties

Adenauer Stiftung, Santiago, 2006) y a los esfuerzos recientes de la Presidenta Bachelet por reemplazarlo el proyecto de ley fue rechazado en mayo de 2008 por no alcanzar el quórum especial requerido debido a la oposición en bloque de la oposición de derecha. 
a empresas mineras extranjeras; un sistema solidario de salud pública; un sistema de pensiones solidario; la restitución de gran parte de los derechos de los trabajadores que fueron suprimidos durante la dictadura a través de un nuevo Código del Trabajo; el reconocimiento de la diversidad cultural del pueblo chileno ${ }^{17}$ o la creación de un Ombudsman o Defensor del Pueblo (sólo muy tardíamente y luego de largas concesiones se generó una institución para los derechos humanos); la ratificación de tratados internacionales sobre derechos humanos.

En cuarto lugar, una distorsión distinta de la democracia electoral tiene que ver con el diferencial de dinero aportado a las campañas electorales y de acceso a los medios de comunicación. En 2004 entra en vigencia la Ley N 19.884 "Sobre Transparencia, Límite y Control del Gasto Electoral", que establece secreto sobre ciertas donaciones y no establece multas significativas para los casos de infracción a los límites al gasto electoral. Por otro lado, tampoco otorga facultades amplias al Servicio Electoral para fiscalizar el cumplimiento de dichos límites. Esta ley fue modificada por la Ley $\mathrm{N}^{\mathrm{o}} 20.053$, que tiene por objeto incorporar algunas nuevas partidas como gastos aceptados y repara el error inicial de no haber incluido el aporte del Estado a las campañas para candidatos a Presidente de la República. ${ }^{18}$

En quinto lugar, cabe señalar la restricción normativa y fáctica del cuerpo electoral. En efecto, por un lado, no existe el derecho de los chilenos en el extranjero para votar, lo que deja fuera del sistema cerca de un millón de ciudadanos potenciales. Los diversos proyectos presentados, que implicarían una reforma constitucional, han sido rechazados por la derecha que no da el quórum necesario para ello. Por otro lado, el sistema actual de inscripción voluntaria y voto obligatorio eleva los costos de la participación y la desincentiva, pues el proceso de inscripción es engorroso, lejano de las personas, en plazos que no guardan relación con las elecciones mismas y, además, conlleva a sanciones a quienes no votan una vez inscritos. Ello ha llevado a un acuerdo entre las dos grandes coaliciones para reformar la Constitución, estableciendo la inscripción automática pero el voto voluntario, lo que es sin duda la más contradictoria y absurda de las fórmulas. Si bien lo primero es un gran avance y parece una medida obvia, lo segundo es un retroceso histórico, porque en Chile ha sido el establecimiento del voto obligatorio, con sanciones para quienes no votan, lo que ha generado la participación político-electoral. Se sabe que el paso del voto obligatorio al voluntario implica a la larga la reducción de la participación electoral, como lo muestran todos los casos históricos y, al mismo tiempo, la elitización del voto, por cuanto tienden a participar los de mayor capital social y cultural. ${ }^{19}$ Ello

17 Un proyecto de reforma constitucional propuesto en 1991 por el Gobierno del Presidente Aylwin, tendiente a que la Constitución reconociera el carácter multirracial y multicultural del pueblo chileno, fue rechazado por esos sectores, justamente cuando América Latina se aprestaba a conmemorar el quinto aniversario de la conquista europea, y hasta el día de hoy no se satisface esta demanda que cuenta con amplísimo apoyo en el país y, especialmente, en los sectores mayoritarios en el Parlamento. Del mismo modo, esa oposición dilató por 18 años la ratificación del Convenio 169 de la Organización Internacional del Trabajo.

18 Corporación Participa. Informe de desarrollo. Proyecto "Transparencia, límite y control del gasto electoral en el marco de las elecciones parlamentarias y presidenciales, Chile 2005". Pág. 3.

19 S. Valenzuela, “¿Cómo reformar el sistema electoral? Reflexiones en torno a un desafío pendiente del retorno a la democracia en Chile". En C. Huneeus (comp.), op. cit. 
tenderá a aumentar lo que hemos llamado la reducción fáctica del electorado que se ha dado en la situación actual (con implicancias en su representatividad), en que sobre el total de la población en edad de votar hubo en la elección de diputados de 2005 un porcentaje de no inscritos de 27,4\% y de votantes de 63\%. En el 2008 el porcentaje de no inscritos alcanzaba a 32,2\% de la población mayor de 18 años, es decir, cerca de 4 millones de personas. La participación electoral de los jóvenes es dramáticamente baja, lo que disminuye la representatividad del electorado, por cuanto los jóvenes entre 18 y 29 años de edad, que en 1998 eran el 36\% del padrón electoral, en 2008 fueron solamente el 8\% del mismo. Ello se modificó apenas para la elección de 2009.

\section{DEMOCRACIA CIUDADANA}

El estudio de la democracia ciudadana y de los derechos ciudadanos, es decir, de la existencia de una comunidad política en que los ciudadanos ejercen sus derechos y participan en las decisiones que la afectan, debe hacerse en relación con las dimensiones electoral y constitucional de la democracia. No se trata sólo de la existencia formal de esos derechos y de una institucionalidad que los garantice, sino de la capacidad efectiva de los ciudadanos de realizarlos. Ello exige, por un lado, la igualdad sustantiva de base socioeconómica y cultural de todos los ciudadanos, de modo que no haya fundamentales diferencias en las capacidades económicas, sociales y culturales para el ejercicio de los derechos iguales para todos. Por otro lado, implica la existencia de capacidades de organización y presión para defenderlos. En síntesis, la igualdad de los derechos ciudadanos y la participación en los asuntos públicos van más allá de la elección de representantes que supone la democracia electoral, pero muchos de los límites de ésta afectan la democracia ciudadana.

Un primer acercamiento respecto del caso chileno en la actualidad se observa a nivel del compromiso que ha suscrito el Estado con la normativa internacional vigente en relación con la promoción y protección de los derechos humanos. En este sentido, existe una serie de normativas aún no ratificadas por el Estado de Chile: la Convención Interamericana sobre la desaparición forzada de personas (la Cámara de Diputados se opuso a hacerlo); el Protocolo adicional a la Convención sobre la Eliminación de la Discriminación contra la Mujer; la Convención sobre la imprescriptibilidad de los Crímenes de Guerra y de Lesa Humanidad; Protocolo de San Salvador, Adicional a la Convención Americana sobre derechos económicos, sociales y culturales. El Estatuto de la Corte Penal Internacional; fue ratificado el 29 de junio de 2009, al que las fuerzas herederas de la dictadura se opusieron por más de 10 años. Para justificar su oposición exigieron una reforma constitucional, que no tenía otro objeto de poder justificar su anterior obstrucción.

Como se observará a continuación, la ausencia de ciertos compromisos básicos por parte del Estado en términos de derechos humanos es determinante tanto a nivel del desarrollo de los derechos civiles y políticos como a nivel de los aspectos económicos y sociales de la ciudadanía. 
Si bien el Estado chileno ha logrado avances sustantivos en materia diplomática en temáticas vinculadas a los derechos humanos, donde destaca el posicionamiento de una chilena en el cargo de presidenta de la Corte Interamericana de Derechos Humanos, o haber sido recientemente electo como miembro del Consejo de Derechos Humanos de Naciones Unidas, ${ }^{20}$ aún es posible presenciar asimetrías respecto del progreso de los derechos formales y de aquellos aspectos sociales, políticos y económicos de la ciudadanía.

Examinaremos los diversos campos de derechos y de democracia ciudadana separadamente: ${ }^{21}$

\section{a. Derechos Civiles}

Libertad de expresión y derecho a la información. La libertad de expresión no sólo implica la facultad de expresar opiniones o pensamientos, sino que además "el derecho al acceso y recibimiento de información que permita a los sujetos la posibilidad de formarse una opinión reflexiva sobre sí mismo y el desarrollo de la sociedad". ${ }^{22}$

En temas vinculados a los derechos humanos en libertad de expresión, el Estado chileno ha sido sancionado por la Corte Interamericana de Derechos Humanos: ${ }^{23}$ a) en 2001, por la censura de la exhibición de la película "La última tentación de Cristo", b) en 2005, por haber censurado -a través del sistema de justicia militar- la publicación de un libro

20 Universidad Diego Portales y Fundación John Merck. 2008. “Informe anual sobre Derechos Humanos en Chile 2008". Santiago: Ediciones UDP, pp. 11.

21 Respecto de la cuestión de la democracia ciudadana, vale la pena recordar algunas observaciones hechas en el taller de debate con la sociedad civil organizado por PARTICIPA en el marco del Proyecto del que forma parte el presente Informe. En primer lugar, la presidenta de una Comisión Asesora Presidencial para la Protección de los Derechos de las Personas -creada para intentar dar alguna solución a las quejas ciudadanas contra abusos o irregularidades de organismos del Estado, en ausencia de un Ombudsman- reconoció su absoluta falta de independencia del Ejecutivo y sostuvo que la mayor cantidad de casos recibidos se han debido a las insuficiencias de las prestaciones estatales en las áreas de salud, seguridad social y seguridad ciudadana. Pero representantes de organizaciones civiles dijeron no conocer la institución. En segundo lugar, un dirigente estudiantil reclamó que la reglamentación de un derecho tan importante, como es el derecho de reunión, estuviese aún reglamentado por normas de los períodos más represivos de la dictadura (Decreto Supremo del Ministerio del Interior $N^{\circ} 1086$, de 16 de septiembre de 1983), lo que a su juicio, apoyado por prácticamente todos los asistentes, constituye "una práctica abiertamente autoritaria y discriminatoria de la movilización estudiantil". Dicho Decreto, modificado días antes de la transmisión del mando (Decreto N 1498 , de 10 de octubre de 1989), fue dictado en los días en que en el país se desarrollaban las llamadas "protestas" contra la dictadura y con el fin obvio de reprimirlas, sigue en pleno vigor, y a él se ajustan los permisos para las marchas de movimientos sociales. Su utilización es vista como una legitimación de un texto que siempre fue repudiado durante el autoritarismo. En tercer lugar, también se criticaron prácticas e instituciones que no son herederas de la dictadura. El mismo dirigente expresó que la Agencia Nacional de Inteligencia -creada por los gobiernos democráticos- está facultada para intervenir en la vida privada de las personas, lo que constituye "abiertamente una práctica antidemocrática". Y otros sostuvieron que se encuentra aún vigente la práctica de la tortura, siendo mapuches algunas de las víctimas.

22 Universidad Diego Portales y Fundación John Merck. 2008. “Informe anual sobre Derechos Humanos en Chile 2008". Santiago: Ediciones UDP, pp. 25.

23 Ubicada en San José, Costa Rica, la Corte Interamericana de Derechos Humanos es una institución judicial autónoma de la Organización de los Estados Americanos cuyo objetivo es la aplicación e interpretación de la Convención Americana sobre Derechos Humanos y de otros tratados concernientes al mismo tema. Ésta fue establecida en 1979. 
sobre inteligencia militar, ${ }_{,}^{24}$ y c) en 2006, por violar el derecho de las personas respecto del acceso a la información pública en materias de interés público.

Pese a lo anterior, en Chile se registran avances relevantes en torno a esta materia, en donde destacan los siguientes: ${ }^{25}$ a) la derogación de las normas constitucionales sobre censura previa (sobre todo las enfocadas a la ratificación de tratados internacionales y de probidad en la función pública (artículos $\left.3^{\circ}, 39,54\right){ }^{26}$ b) la derogación de las normas sobre censura contenidas en la Ley de Seguridad Interior del Estado ( $\left.\mathrm{N}^{\circ} 12.927\right)$, c) la derogación de las normas criminales sobre desacato ${ }^{27}$ y d) la reforma constitucional a la regulación de la libertad de expresión y derecho de reunión durante los estados constitucionales de excepción (Ley $\mathrm{N}^{\circ} 18.825$ ). Además de dichas reformas, otro aspecto relevante en materia de libertad de expresión corresponde a la implementación de una nueva normativa relativa al acceso a la información pública, como complemento de las normas sobre transparencia y probidad contenidas en el ámbito constitucional, amparado por el artículo $8^{\circ}$ de la Constitución Política de Chile. Se trata de la Ley de Transparencia a la que nos referimos más arriba.

La libertad de expresión tiene una importante relación con la ratificación del derecho a la información..$^{28}$ En Chile, la Ley $N^{\circ} 19,133$, sobre Libertades de Opinión y de Información y sobre Ejercicio del Periodismo, ratifica esta condición. Sin embargo, esta libertad de expresión y el derecho a la información están impedidos a través de la concentración

Caso Palamara Iribarne vs. Chile, sentencia de 22 de noviembre de 2005. Causa $\mathrm{N}^{\mathrm{o}} 464$ ante el Juzgado Naval de Magallanes por los delitos de desobediencia e incumplimiento de deberes militares. Ver hechos del caso en párrafos 63 a 63.71 de la sentencia comentada. Causa $N^{\circ} 471 / 93$ ante el Juzgado Naval de Magallanes por el delito de desacato. Ver párrafos 63.72 a 63.93 de la sentencia. Chile derogó el delito de desacato de la Ley de Seguridad del Estado en el año 2001. A su vez, la Ley No 20.048, de 2005, derogó los artículos 263 del Código Penal que establecía el delito de injuria contra la autoridad y 265 que establecía el delito de desacato o injuria grave contra la autoridad. A comienzos del año 1993 cuando al señor Humberto Palamara Iribarne, oficial retirado de la Armada de Chile, se desempeñaba como empleado civil a contrata de la Armada de Chile, se le prohibió publicar su libro llamado "Ética y Servicios de Inteligencia", que abordaba aspectos relacionados con inteligencia militar y con la necesidad de adecuarla a ciertos parámetros éticos. El hecho de escribir este texto e intentar su publicación, y haber realizado declaraciones en prensa al respecto, dieron origen al procesamiento del señor Palamara por los delitos de incumplimiento de deberes militares y desobediencia y por el delito de desacato. También destaca el caso de la censura del "Libro Negro de la Justicia Chilena" en 1999.

25 Todas estas reformas constitucionales fueron realizadas el año 2005. Biblioteca del Congreso Nacional de Chile. Documento: www.bcn.cl

26 En cuanto al acceso a la información, la reciente reforma constitucional (Ley $\mathrm{N}^{\circ}$ 20.050) estableció como fundamento de la actuación de la administración, la publicidad de sus actos y la necesidad de dar a conocer los fundamentos de sus resoluciones (Art. $8^{\circ}$ reformado de la Constitución Política). Además, se abolió la última forma de censura contenida en la Constitución, la censura cinematográfica (Art. $19 \mathrm{~N}^{\circ} 12$ ) y se reformó el numeral $\mathrm{N}^{\circ} 25$ del artículo 19 reconociéndose la libertad de creación artística.

27 Pese a que se mantuvo la figura jurídica en el Código de Justicia Militar. La Ley $\mathrm{N}^{\mathrm{o}}$ 20.048, publicada en el Diario Oficial de 31 de agosto de 2005, modificó el Código Penal y el de Justicia Militar en lo relativo al desacato. Se derogaron los artículos 263 y 265, que tipificaban el desacato propiamente tal; se sustituyó el artículo 264, que calificaba como desacato las amenazas y las perturbaciones al orden en las sesiones de los cuerpos colegisladores, en las audiencias de los tribunales de justicia, y las amenazas e injurias a parlamentarios por las opiniones manifestadas en el Congreso, a los jueces por sus fallos y a las autoridades en el ejercicio de sus cargos. Se eliminó también el artículo 268, relativo a las sanciones contra quien ocasionare tumulto en el despacho de una autoridad.

28 Organización de Naciones Unidas. Oficina del Alto Comisionado para los Derechos Humanos. “Instrumentos Internacionales de Derechos Humanos". Documento: http://www.derechos.org/nizkor/ley/. 
monopólica de los medios de comunicación escritos en dos grandes consorcios, la concentración de los medios radiales (por ejemplo, la mitad del mercado en manos del grupo español Prisa) y la ausencia de pluralismo en los medios televisivos. Además, tanto el Consejo Nacional de Televisión como el de la Televisión Pública excluyen a un sector de la población al estar conformados por un acuerdo del Senado donde prima un empate político excluyente. En esta materia el Estado no ha podido asumir un rol más activo: sólo ha sido fiscalizador de la permanencia de la competencia bajo los parámetros del mercado, a través de la labor que lleva a cabo el Tribunal de Defensa de la Libre Competencia (TDLC).

Derechos humanos específicos de género. Chile ratificó la "Convención para la eliminación de la discriminación contra la mujer", CEDAW, en 1989, en la cual se reconoce un conjunto de derechos relacionados a la salud sexual y reproductiva, y es aplicable a todas las mujeres, tanto ciudadanas como no ciudadanas: ${ }^{29}$ en su artículo 11 reconoce el derecho a la protección de las madres antes y después del parto, en su artículo 12 el derecho a la salud y a la atención de salud, en sus artículos 10,12,14 y 16 el derecho a la información, asesoramiento y servicios de planificación familiar, y en el artículo 16 el derecho a decidir libre y responsablemente el número y espaciamiento de sus hijos.

El último informe enviado por Chile al Comité de la CEDAW en 2004 fue devuelto con múltiples observaciones, en especial en materia de derechos sexuales y reproductivos, respecto del trato deshumanizado de las complicaciones del aborto inseguro y sobre la preocupación del Comité por la penalización y prohibición absoluta del aborto. En la actualidad, la aprobación del protocolo facultativo de la convención que permite la recepción y procesamiento de quejas individuales, no se ha llevado a cabo. La persistencia del incumplimiento ha continuado aun cuando el SERNAM tiene el mandato legal por medio de la Ley $\mathrm{N}^{\circ} 19.023$ de "garantizar el cumplimiento de la Convención". Este hecho constituye una flagrante transgresión del derecho a la salud y a la salud sexual y reproductiva de todas las mujeres habitantes en el territorio nacional, incluyendo a las nacionales y no nacionales. Un claro ejemplo de atropellos a los derechos sexuales y reproductivos de las mujeres es lo ocurrido con el Tribunal Constitucional en 2008 sobre la píldora del día después, a lo que ya nos referimos.

Respecto de la inclusión de la mujer en el mercado laboral, vale la pena recordar que si bien Chile en el ranking general de competitividad realizado por el Foro Económico Mundial aparece en el lugar 27 entre 125 países medidos, en lo relacionado a la situación laboral de las mujeres desciende al puesto 110. El crecimiento económico que ha experimentado el país trajo como consecuencia un aumento del empleo, en especial del femenino, lo cual permite sostener que el desempeño económico de Chile conlleva a una disminución de la brecha de género en cuanto a participación laboral. Durante la década de los 90 la tasa de crecimiento del empleo femenino fue mayor que la del masculino, de modo que se incorporan durante este periodo más de medio millón de mujeres al mercado laboral. 
Gráfico 1: Evolución de la tasa de participación por sexo 1990-2006

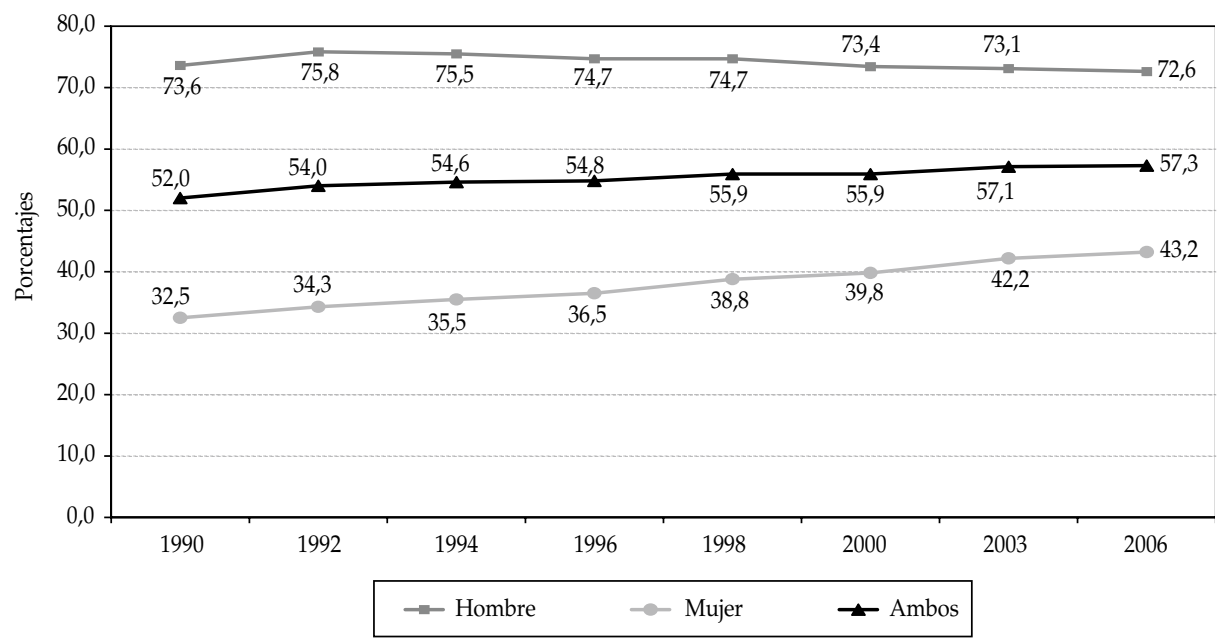

Fuente: Encuesta CASEN 2006.

Sin embargo, la tasa de participación femenina sigue siendo baja en comparación con la de otros países de América Latina y el Caribe y, por lo tanto, muy lejana a las tasas de participación alcanzadas por los países desarrollados.

Gráfico 2: Tasa de participación de las mujeres en la región. Tres primeros trimestres, 2006

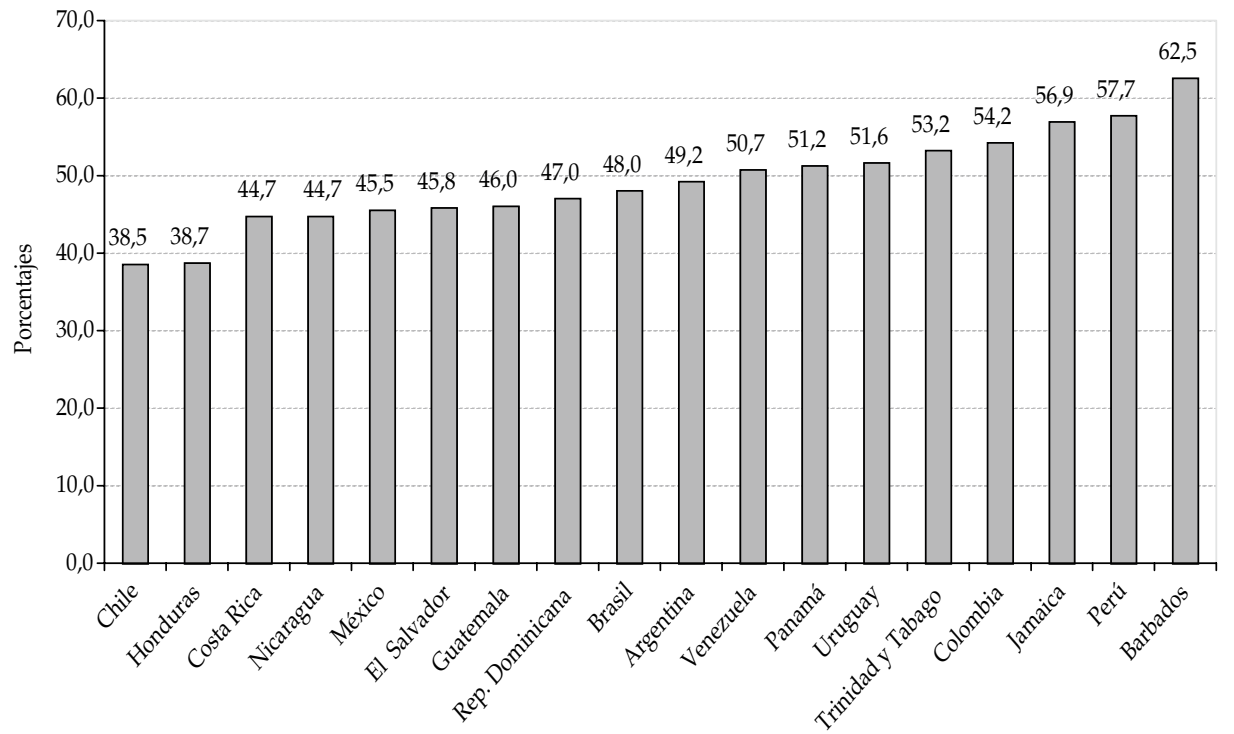

Fuente: Elaboración OIT con base en información oficial. 
Con respecto al ingreso de las mujeres al mercado de trabajo, es posible establecer una serie de factores que determinan la participación laboral femenina. Uno de estos determinantes se refiere a actitudes y valores culturales referidos a las condiciones en que estas mujeres se incorporan al mundo laboral, debido a la existencia de estereotipos sociales que ven a la mujer como una fuerza de trabajo secundaria. Además, son consideradas como personas con menor capacidad, preparación y experiencia para el desempeño de ciertas ocupaciones y se les asocia un costo mayor debido a su papel en la reproducción biológica. De esta manera, las mujeres son discriminadas en cuanto al acceso al trabajo remunerado, a la calidad de los empleos y reconocimiento de sus derechos laborales, lo cual produce segregación ocupacional. Otro factor que influye en la incorporación de la mujer al trabajo es la estructura familiar. Un estudio realizado por MIDEPLAN señala que las mujeres inactivas declaran que su situación es causada sobre todo por los quehaceres domésticos. Este hecho se contrasta con el caso de los hombres, los cuales declaran que su inactividad se debe sobre todo a razones de estudios.

Aunque la presencia de hijos sigue siendo un factor determinante en la participación de la mujer en el trabajo, vemos algunos avances. Al analizar los últimos dos censos (1992 y 2002), observamos que en todas las edades se produce un aumento de la tasa de participación femenina en el trabajo, el cual es en especial notorio entre las mujeres de 25 a 39 años, edad reproductiva de la mujer. De esta manera se comienza a demostrar que durante esta década se han creado mecanismos que permiten la conciliación de la vida laboral con la vida familiar.

La educación también influye de forma directa en la participación de la mujer en el trabajo. A medida que aumentan los años de estudio de las mujeres se observa que aumenta la tasa de participación, lo cual manifiesta que las mujeres con menor educación presentan mayores obstáculos para la inserción laboral, creándose un circulo vicioso, ya que son estas mujeres las que presentan mayores necesidades económicas y, por lo tanto, presentan una mayor necesidad de trabajar.

En relación con el salario se observan importantes diferencias entre hombres y mujeres. En general existe una relación directa y positiva entre los ingresos y los años de estudio realizados. Sin embargo, si analizamos los datos comparando según sexo encontramos que a mayor año de escolaridad se acrecienta la brecha entre los salarios recibidos por hombres y mujeres por un mismo trabajo. "Mientras que una mujer que tiene entre 0-3 años de estudios gana un $18,6 \%$ menos que un hombre con el mismo nivel de estudio que ella, una mujer con 13 y más años de estudio gana $35,7 \%$ menos que un hombre con el mismo nivel de estudio". ${ }^{30}$ 
Gráfico 3: Ingresos de la mujer como porcentaje del ingreso de los hombres según nivel educacional alcanzado

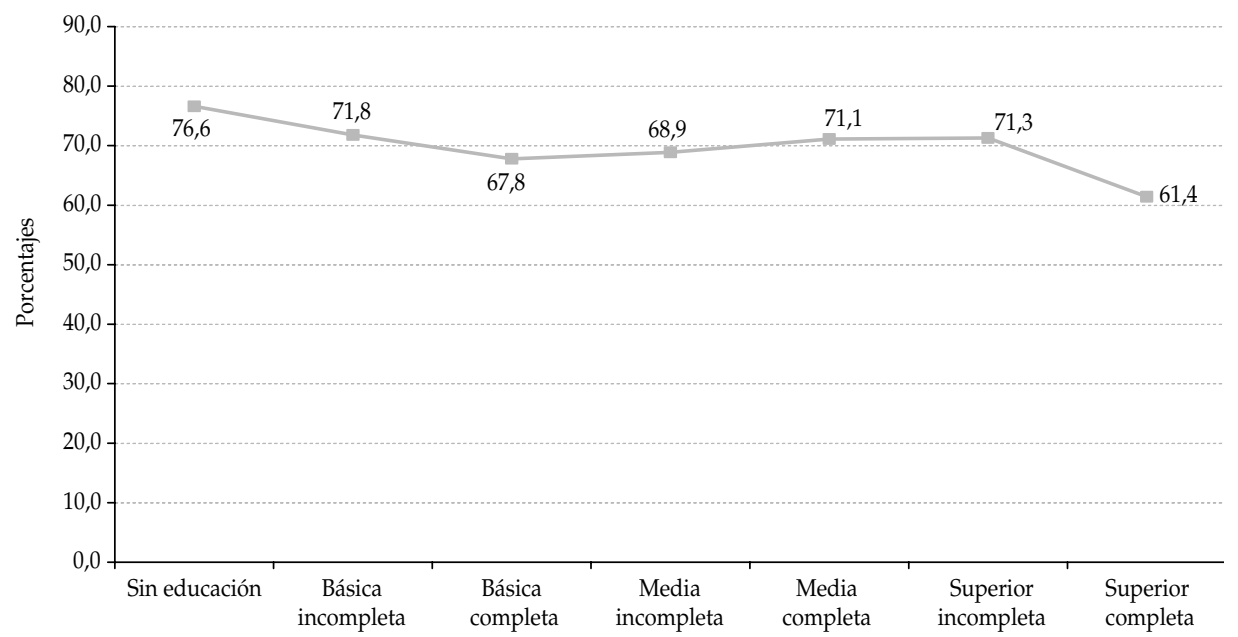

Fuente: Encuesta CASEN 2006.

En términos generales, la brecha salarial entre hombres y mujeres se estima en $23,9 \%$, de modo que las mujeres alcanzan sólo un 76,1\% del salario de los hombres. Esta brecha salarial entre hombres y mujeres se expresa en todos los grupos ocupacionales, intensificándose en los extremos, de modo que es en los cargos directivos donde se da una mayor diferencia de ingresos, constatándose que las mujeres reciben sólo un $62,7 \%$ del salario de los hombres. En el grupo ocupacional de los trabajadores(as) no calificados(as), grupo con las menores remuneraciones en el campo ocupacional, las mujeres alcanzan el 81,5\% de las remuneraciones de los hombres.

En conclusión, se puede constatar que las problemáticas que subyacen la inserción laboral de la mujer en el mercado en el caso chileno permiten constatar desigualdades a nivel de acceso y remuneraciones, lo que muestra una ausencia de democracia laboral en términos de género, ya que no existen las condiciones necesarias que garanticen igualdad entre hombres y mujeres en el mercado del trabajo chileno.

Por último y con relación a la participación política de la mujer, todavía su participación en el Parlamento y en las direcciones de las organizaciones políticas sigue siendo muy minoritaria, aunque representan más de la mitad del electorado. No existe ley de paridad o de cuotas aunque algunos partidos consagran este sistema para sus directivas y están en el Parlamento proyectos de ley al respecto. Su participación en los altos puestos del Poder Judicial y del Ejecutivo es también muy minoritaria, con la excepción del primer gabinete de la Presidenta Michelle Bachelet que fue paritario, pero no existe ninguna institucionalidad que garantice este principio.

Derechos humanos específicos de minorías sexuales. En el caso de las minorías sexuales, aún se constatan formas de discriminación por parte de instituciones públicas tales como 
municipalidades, Fuerzas Armadas y de orden. Pese a ello, es relevante constatar la vigencia del principio de no discriminación consagrado en la Constitución Política de Chile (artículo 19, $\mathrm{N}^{\circ}$ 2) y que en el Derecho Internacional de los Derechos Humanos se ha entendido como un principio fundamental e integrante del Derecho Internacional. En efecto, a partir de la Declaración Universal de Derechos Humanos de 1948, la cláusula de no discriminación se ha incluido en virtualmente en todos los instrumentos universales de protección de los derechos humanos. ${ }^{31} \mathrm{Tal}$ como se ha denunciado en Informes de Derechos Humanos, en el Estado chileno aún existe discriminación dado que no se han desarrollado normativas específicas respecto de la situación de dichas minorías. En la campaña presidencial de 2009 éste fue un tema privilegiado y todas las candidaturas, incluida la del candidato de derecha triunfante, se comprometieron a modificar la legislación y a aceptar alguna forma de reconocimiento de parejas homosexuales en materia patrimonial, otras fueron más avanzadas yendo más allá del tema patrimonial. Existen dos precedentes contradictorios en el plano judicial recientemente en esta materia. En uno se le quitó la tuición de los hijos a una jueza por ser lesbiana, en el otro se le otorgó la tuición a un padre (lo que en sí mismo es poco frecuente) que vivía con su pareja homosexual.

Derechos humanos específicos de los pueblos indígenas. Respecto de la situación de los derechos de los pueblos indígenas en Chile, el contexto ha estado marcado por el conflicto entre el Estado y algunas comunidades mapuches. La situación de conflictividad y tensión social en la Araucanía, que ha sido denunciada por numerosas organizaciones, tanto nacionales como internacionales, ha dominado la agenda pública en esta materia. ${ }^{32}$

En mayo de 1990, bajo el primer gobierno democrático presidido por Patricio Aylwin, se crea la Comisión Especial de Pueblos Indígenas (CEPI), la que prepara un programa de trabajo orientado a proponer un anteproyecto de Ley Indígena y el desarrollo de un programa de acción para atender las necesidades más urgentes de la población indígena.

En 1993 se promulga la Ley N N 19.253 o Ley Indígena, estableciendo normas sobre protección, fomento y desarrollo de los pueblos indígenas, fundamentándose en el reconocimiento a la diversidad cultural y étnica; el reconocimiento jurídico de las comunidades; el fomento a la participación; la discriminación positiva; la protección y ampliación de las tierras indígenas; la focalización de recursos del Estado para el desarrollo; la creación del Fondo de Tierras y Aguas Indígenas; la conciliación y arbitraje; el reconocimiento, respeto y protección de las culturas indígenas; el desarrollo de un sistema de educación intercultural bilingüe; mecanismos de autoidentificación de indígenas urbanos y migrantes; y el reconocimiento a las particularidades de los pueblos indígenas. El mismo año, mediante la promulgación de esta Ley se crea la Corporación Nacional de Desarrollo Indígena (Conadi), organismo encargado de promover, coordinar y ejecutar la acción 2008". Santiago: Ediciones UDP, p. 434.

32 Universidad Diego Portales y Fundación John Merck. 2008. “Informe anual sobre Derechos Humanos en Chile 2008". Santiago: Ediciones UDP, p. 362. 
del Estado a favor del desarrollo integral de las personas y comunidades indígenas en los ámbitos económico, social y cultural, así como de impulsar su participación en la vida nacional.

Bajo el gobierno de Eduardo Frei se crea la Comisión Asesora en Temas de Desarrollo Indígena con el objeto de acoger las demandas y aspiraciones de las comunidades del país. Más de 4.000 dirigentes y más de 2.000 comunidades y asociaciones participaron en el proceso que dio paso a un Plan de Desarrollo de Inversión tendiente a acoger algunas de las demandas planteadas. Se establece el 24 de junio como Día Nacional de los Pueblos Indígenas.

Bajo el gobierno de Ricardo Lagos se forma un Grupo de Trabajo para los Pueblos Indígenas, para recoger las demandas indígenas del país. El 31 de mayo de 2000, el Presidente responde el informe del Grupo de Trabajo para los Pueblos Indígenas con una Carta a los Pueblos Indígenas de Chile en la que anunció sus " 16 medidas", dentro de las cuales se establece la creación de la Comisión de Verdad Histórica y Nuevo Trato hacia los Pueblos Indígenas, destinada a asesorar al Presidente de la República y a efectuar recomendaciones para una política de nuevo trato de Estado para un reencuentro de la sociedad chilena. En marzo de 2001 se crea la Coordinación de Programas y Política Indígena. Creación de la Comisión Asesora Presidencial para la Coordinación de Políticas y Programas Indígenas y su dirección Ejecutiva, la que tiene por objetivo prestar asesoría al Presidente de la República. En abril de 2004, sobre la base de las recomendaciones del Informe de la Comisión de Verdad Histórica y Nuevo Trato hacia los Pueblos Indígenas, se anuncia la Política de Nuevo Trato 2004-2010 (Ley No 19.882), focalizando el trabajo en tres ejes: Derechos de los Pueblos Indígenas, Desarrollo con Identidad y Adecuación del Estado a la Diversidad Cultural.

Los gobiernos de la Concertación, incluido el de la Presidenta Bachelet, han enviado al Parlamento distintas iniciativas tendientes a lograr el reconocimiento constitucional de los pueblos indígenas y solicitado la ratificación del Convenio 169 sobre Pueblos Indígenas y Tribales de la Organización Internacional del Trabajo (OIT). La ratificación de este Tratado no ha ido acompañada de todos los mecanismos de consulta a los pueblos indígenas que el Tratado exige.

Sin embargo, pese a los avances logrados en materia de integración y reconocimiento de los derechos fundamentales de los pueblos originarios y pese a que en el gobierno de Bachelet se ha decidido no usar la ley antiterrorista contra los mapuches, aún existen casos empíricos de discriminación y atentado a dichos derechos fundamentales. Tal como lo constata el informe de Amnistía Internacional, los casos empíricos de tortura en Collipulli y los hechos de detención y tortura mapuche registrados el 5 de mayo de 2008 en la Región de Los Lagos, más el emblemático caso de la detención de la documentalista Eliana Varela, la Ley de control antidelincuencia y la normativa de control interno en Carabineros de Chile constituyen muestras de que los aparatos institucionales avalan la represión y la tortura por parte de la autoridad policial en Chile. Así, en su calidad de organismo de derechos humanos, se mencionan como casos relevantes ciertas querellas 
presentadas contra el Estado chileno por el desarrollo de detenciones arbitrarias y prácticas de tortura el 10 de junio de $2008 .{ }^{33}$ Ello además tiene su expresión en el rechazo a reclamaciones de comunidades indígenas contra proyectos de inversión emplazados en tierras ancestrales que atentan contra sus derechos medioambientales. En este sentido puede afirmarse que en materia de derechos indígenas, la situación es contradictoria en la medida que pese a grandes avances en cuestiones de desarrollo y reconocimiento, la sociedad chilena continúa desconociendo los derechos colectivos de los pueblos indígenas y también se vulneran en varios casos derechos básicos de sus integrantes. ${ }^{34}$

Derechos civiles de presos. Pese al gran avance en construcción de cárceles y otras materias penitenciarias, un informe reciente ${ }^{35}$ confirmaba ciertas denuncias de jueces revelando que los recintos penitenciarios no cumplen con los estándares internacionales, persistiendo "graves condiciones de hacinamiento, falta de atención médica adecuada, muertes, tortura y malos tratos, corrupción de gendarmes y, en general, de una falta de transparencia y de un control apropiado de la gestión de las cárceles". Existen serias limitaciones al acceso a la información. Esta situación es aún más dramática en relación con la situación de niños, niñas y adolescentes infractores de ley, constatando que "los problemas más generalizados dicen relación con la calidad de la infraestructura de los centros, su ubicación geográfica, la alimentación de los menores, las condiciones del derecho a visitas y el acceso a prestaciones de salud idóneas. También persisten la tortura y los malos tratos, incluyendo el uso de celdas de castigo en vulneración de los estándares internacionales, y los abusos sexuales". Los programas de rehabilitación son absolutamente ineficaces.

\section{b. Derechos Políticos}

Existencia de poderes fácticos "de jure". Hemos indicado más arriba cómo el Tribunal Constitucional de Chile, órgano del Estado chileno, autónomo e independiente de toda otra autoridad o poder, con naturaleza jurídica de tribunal colegiado, ha impugnado las normas nacionales de regulación de la fecundidad a pesar de los requerimientos de la sociedad civil y mujeres de hacerse parte del proceso (caso de la píldora del día después). ${ }^{36}$

33 Datos extraídos del sitio web Amnistía Internacional: www.altoahi.cl

34 Ver una buena síntesis de la materia en "Política indígena y "re-conocer". Entre el discurso y la realidad". José Aylwin. Revista Mensaje, mayo 2009, Santiago, Nº 578.

35 Universidad Diego Portales y Fundación John Merck. 2008. “Informe anual sobre Derechos Humanos en Chile 2008". Santiago: Ediciones UDP.

36 Dicho fallo constituía un retroceso en el reconocimiento de la autonomía sexual y reproductiva de las mujeres, perpetuando además las condiciones generalizadas de discriminación entre las mujeres pobres y ricas en Chile. Aunque en el calor de la campaña presidencial de 2009 se logró finalmente el acuerdo que permite la distribución en los consultorios públicos de la píldora del día después, aunque poniendo como condición la información a los padres o algún adulto responsable. Mencionamos aquí este fallo como prueba de la existencia de poderes fácticos de jure. 
Sistema electoral. Ya hemos indicado cómo el sistema binominal deja fuera de la representación parlamentaria a un sector significativo de la sociedad chilena y cómo el sistema de inscripción desincentiva la participación política.

\section{c. Dimensiones económicas y sociales de la ciudadanía}

Desigualdad social. La principal tensión que alcanza el desarrollo socioeconómico chileno, que bajo los gobiernos de la Concertación ha obtenido grandes logros en la superación de la pobreza, en el establecimiento de una política de salud basada en derechos, en la reforma previsional privilegiando a mujeres y sectores pobres, tiene que ver con la desigualdad, una de cuyas principales expresiones es la distribución de ingresos.

Los datos de crecimiento económico no son equiparables con la distribución del ingreso, en que se mantiene un alto índice de Gini, sin desmerecer que ha disminuido a partir de 1990, desde 0,554 a 0,522. ${ }^{37}$ Chile es uno de los países de América Latina con las más altas tasas de desigualdad.

Cuadro 2: Coeficiente Gini. Distribución del ingreso. Chile

\begin{tabular}{ccc}
\hline Chile & Período & $\begin{array}{c}\text { Índices de } \\
\text { concentración }\end{array}$ \\
\hline 1990 & Gini \\
1996 & 0,554 \\
2000 & 0,553 \\
2003 & 0,559 \\
2006 & 0,550 \\
\hline
\end{tabular}

Fuente: CEPAL: Panorama Social de América Latina 2007.

El gobierno de la Presidenta Bachelet constituyó el 23 de agosto de 2007 el Consejo Asesor Presidencial para el Trabajo y la Equidad, con el objeto de desarrollar políticas y propuestas que apunten al progreso y desarrollo en el mundo laboral de una forma más ecuánime en Chile. El Consejo fue integrado por 48 expertos del más alto nivel en los temas a dialogar y representan a las distintas entidades del quehacer nacional, tanto de la esfera política como la empresarial, sindical, religiosa y académica. Fue presidido por el economista Patricio Meller. Una encuesta realizada por este Consejo muestra que un $75 \%$ de la población piensa que no tiene incidencia sobre el salario que percibe, existe un bajo porcentaje que sostiene una percepción satisfactoria de sus capacidades individuales de negociación salarial (25\%), hay una tendencia neta a favor 
Gráfico 4: Coeficiente de Gini a nivel mundial. Chile y el resto del mundo

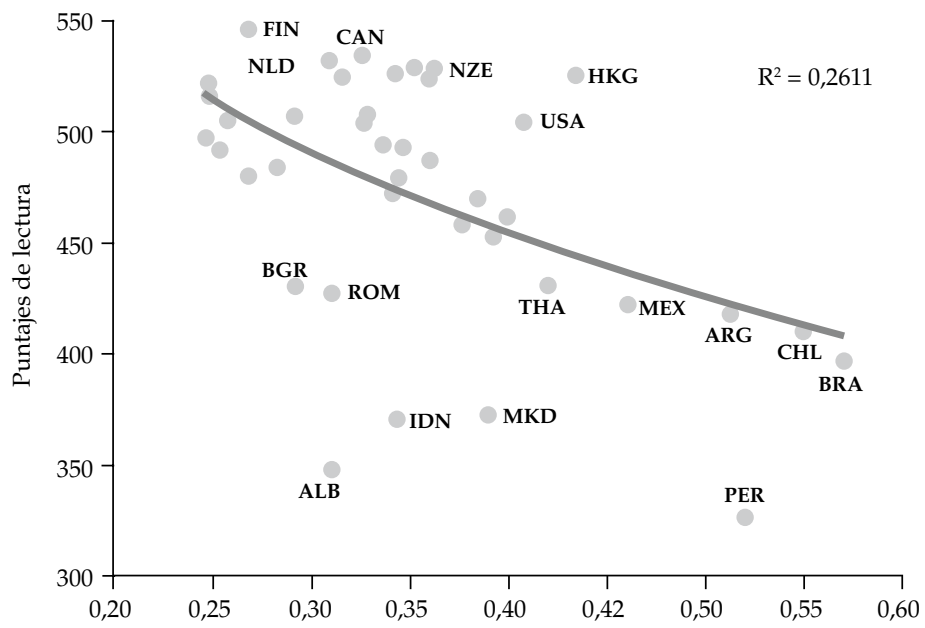

Fuente: CEPAL: Panorama Social de América Latina 2007.

de la equidad sobre el crecimiento, de la participación del Estado en la economía y de cambiar el modelo económico.

La educación es un campo importante en el que se produce y reproduce la desigualdad social. La encuesta Casen 2006 señala que se ha producido un importante incremento en los años de escolaridad de la población de 18 años y más (respecto a 1990) y una significativa reducción de brechas en zonas urbanas y rurales (entre el 2003 y el 2006). También esto es válido cuando se hace el análisis por deciles de ingreso autónomo per cápita, siendo los primeros donde se presenta el mayor incremento. Pese a ello, los indicadores muestran una enorme desigualdad, que se ilustra, por un lado, en el gasto por alumno que es diez veces más alto para los niños de mayores ingresos respecto de los de menor ingreso y, por otro, en los rendimientos según establecimiento. Por ejemplo, en la Prueba de Selección Universitaria, la diferencia entre provenir de una familia con padres o tutores profesionales es de 100 puntos con respecto a un niño que proviene de una familia sin padres profesionales. Ello quiere decir que estas diferencias propias del ambiente de crianza no serán superadas en las sucesivas etapas escolares.

Además, la percepción de la opinión pública es que las desigualdades no disminuyen. Todo ello tiene dos efectos en la calidad de la democracia. Por un lado, desincentiva la participación política. Por otro, genera condiciones distintas de ejercicio de la voluntad popular en que los ciudadanos no tienen una igualdad real.

Institucionalidad laboral. La enorme asimetría de poder entre las organizaciones sindicales y patronales limita el carácter social de la democracia. En cuanto a sindicalización y derecho de huelga, a pesar de que existe una legislación desde el año 2000 y reforzada el año 2001 con la Ley $N^{\circ} 19.759$, aun el año 2008 fueron sancionadas 20 empresas o empleadores por prácticas sindicales. Las tasas de sindicalización no alcanzan al $10 \%$ de 
la fuerza de trabajo, un porcentaje muy bajo tiene acceso a la negociación colectiva y el derecho a huelga está limitado, lo cual resta autonomía a los actores laborales. La mera existencia de la ley no parece suficiente, por un lado sanciona las prácticas antisindicales pero restringe demasiado el actuar de los actores laborales para ejercer su derecho de huelga. De hecho, "la ley laboral chilena sólo permite la huelga en la etapa posterior a la negociación directa de las partes, y como una medida de acción directa vinculada única

y exclusivamente a la negociación o renegociación de un contrato colectivo". ${ }^{38}$ Una de las limitaciones más importantes se encuentra en la Ley de Seguridad Interior del Estado $\mathrm{N}^{\mathrm{o}}$ 12.597, que establece la huelga como un delito en determinadas circunstancias, lo cual va en contra de las tendencias de desarrollo del derecho internacional.

\section{d. Participación ciudadana}

La ausencia de mecanismos de participación en la sociedad chilena tiene su origen en la ausencia de consenso sobre la Constitución, su legitimidad de origen, su contenido y su representación o no de la voluntad del pueblo chileno, así como en la permanencia de leyes y prácticas que obstaculizan la movilización social

Con respecto a este tema, se puede observar el índice que construye la Corporación Participa para medir participación en términos globales. Según este índice, que incorpora aspectos de los distintos tipos de participación, el promedio de participación ha disminuido desde un 5,5 a un 4,5 entre los años 2004 y 2005:

Políticas públicas. La participación ciudadana en políticas públicas corresponde a la acción a través de la cual la ciudadanía, tanto organizada como de forma individual, se hace parte de los procesos de toma de decisiones sobre cuestiones que le afectan. La pertinencia y la eficacia de las políticas públicas dependen del protagonismo de los ciudadanos en su diseño, ejecución y evaluación. Por ello, las debilidades sostenidas y crecientes en los mecanismos de participación asociados a los ámbitos decisionales y consultivos generan desconfianza entre la ciudadanía y los poderes públicos.

En Chile se observa la ausencia de espacios institucionales de participación de la ciudadanía. Sobre este punto, el país se ha caracterizado por mantener una estructura institucional de carácter vertical y centralizada, tal como se refleja en la Ley Orgánica Constitucional No 19.175 sobre Gobierno y Administración Regional, la cual sostiene que incluso las autoridades regionales (gobernaciones e intendencias) deben ser nombradas por el poder central. El propio Estado chileno, frente al tema de la participación, no tiene una posición homogénea, habiendo diferencias entre los núcleos estratégicos de decisión política y económica, los ministerios tradicionales de corte social y los programas innovadores, con una total ausencia de estructuras de participación regional y un ámbito muy limitado a nivel municipal. En este sentido, en agosto de 2008 se publicó un nuevo Instructivo Presidencial de Participación Ciudadana en torno a cuatro mandatos válidos para todos los ministerios: a) establecer una normativa general sobre participación

38 Universidad Diego Portales y Fundación John Merck. 2008. “Informe anual sobre Derechos Humanos en Chile 2008". Santiago: Ediciones UDP, p. 139. 
ciudadana; b) rendir una cuenta anual de gestión y ejecución presupuestaria; c) diseñar mecanismos para establecer Consejos Consultivos de la Sociedad Civil y d) poner a disposición de la ciudadanía sus planes, programa y proyectos. ${ }^{39}$

El proyecto de ley sobre organizaciones de la sociedad civil enviado por el Presidente Lagos todavía está en trámite y, por lo demás, se trata más de un sistema de registro y financiamiento de organizaciones que de un mecanismo de participación en la formulación de políticas públicas.

Nivel local. A niveles locales, los Planes Reguladores Comunales ${ }^{40}$ consideran la participación ciudadana como requisito para su aprobación por el concejo municipal respectivo. Si bien el plano regulador constituye una instancia deliberativa que permite a la comunidad desarrollar capacidades asociadas a la legitimación de procesos vinculados al desarrollo comunal, el sistema no garantiza fórmulas plebiscitarias regulares y existen problemas significativos en los temas medioambientales. ${ }^{41}$ En este sentido, la participación de la comunidad a través de las observaciones que los ciudadanos puedan realizar en las evaluaciones sociales de impacto medioambiental no tiene real incidencia. ${ }^{42}$

En síntesis, si bien existen experiencias aisladas y crecientes de participación, ${ }^{43}$ no existe un sistema institucionalizado que asegure la participación a niveles local, municipal, regional y nacional.

\section{CONCLUSIÓN}

Desde nuestra perspectiva, la democracia constitucional es la dimensión eje en todo régimen de este tipo, porque define el carácter esencial de la democracia como expresión de la soberanía popular, el que a su vez se define en la Constitución como el consenso fundamental en torno a los principios o fundamentos de convivencia de una sociedad. Chile es el único país en las olas recientes de democratización que hereda una Constitución de la dictadura previa y que, pese a sus reformas bajo los gobiernos democráticos, no ha generado una Constitución democrática, es decir, no ha tenido su

39 De la Maza, Gonzalo. “Estado actual y desafíos para la institucionalización de la participación ciudadana en Chile". Texto publicado en G. Delamaza y D. Flores (ed.), Gestión Municipal Participativa. Universidad de Los Lagos, abril 2009.

$40 \quad$ Ley General de Urbanismo y Construcciones. Disponible en: www.bcn.cl

41 Portal Valenzuela, Belfor. "Proposición Metodológica para la Evaluación del Impacto Ambiental de los Planes Reguladores Comunales". Disponible en sitio web: http://www.vrid.usach.cl/pub/Belfor\%20Portal.pdf USACH

42 Sabatini, Francisco \& Sepúlveda, Claudia \& Blanco, Hernán. “Participación Ciudadana para enfrentar conflictos medioambientales. Desafíos para el Sistema de Evaluación de Impacto Medioambiental". Disponible en el sitio: http://www.cipma.cl/Participacion_ciudadana_conflictos_ambientales.pdf . Dos casos emblemáticos contemporáneos en este sentido, fueron el de la Planta Celulosa en Valdivia y el caso de la Costanera Norte en Santiago. En el primer caso la comunidad rechazó los sistemas de evaluación medioambiental y en el segundo los copó.

43 Existe, en los dos últimos años, una interesante experiencia de creación de Consejos Vecinales para el programa de revitalización de 200 barrios en todo el país a través del Ministerio de Vivienda y Urbanismo., aunque también sin institucionalización permanente. Ver Ministerio de Vivienda y Urbanismo y Observatorio Social Universidad Padre Alberto Hurtado, “Recuperando barrios de Santiago”. Folleto. Santiago 2008. 
"momento constitucional". ${ }^{44}$ Dicho de otra manera, el aspecto previo a resolver es el de la legitimidad constitucional: ¿De qué manera la naturaleza del sistema constitucional chileno y su incidencia en la democracia electoral y ciudadana representan la voluntad del pueblo chileno?

Recordemos que esta Constitución fue impuesta por Pinochet en un plebiscito fraudulento en 1980, pero fue el marco institucional en el que se desarrolló el plebiscito de 1988 que terminó con la dictadura y abrió el camino a la elección de gobiernos democráticos y a lo que hemos llamado democracia incompleta. Los términos de esa Constitución y el sistema electoral por ella diseñado, que difícilmente podrían ser llamados democráticos incluso cuando las elecciones sean formalmente libres, limpias y exentas de fraude, impiden que la Constitución sea modificada en aquello que los partidarios de la dictadura consideran contrario a sus intereses. En los términos de los artículos 1 común a los dos Pactos de Naciones Unidas sobre Derechos Humanos, el pueblo chileno no ha recuperado "su derecho de libre determinación", en cuya virtud los pueblos "establecen libremente su condición política y proveen asimismo a su desarrollo económico, social y cultural". En otras palabras, no existe en Chile un consenso constitucional básico.

Respecto de la democracia electoral, es evidente que las elecciones chilenas son libres, limpias y no fraudulentas. Pero el sistema electoral establecido en la Constitución consagra un empate entre la primera minoría y la mayoría, dándole a la primera, que es la derecha constituida bajo la dictadura, un poder de veto sobre todas aquellas cuestiones que permitan romper con el modelo institucional, económico y social heredado, además de excluir la posibilidad de una tercera fuerza distinta a los bloques de gobierno y oposición. Este empate político se reproduce en todas las instituciones cuyos miembros son nombrados o propuestos por el Senado.

Otras distorsiones de la democracia electoral se manifiestan en la concentración de medios de prensa que impide el pluralismo de información, el poder diferencial del dinero en las campañas electorales apenas mitigado por las nuevas normativas.

Por último, cabe señalar la reducción normativa y fáctica del cuerpo electoral y de los resultados democráticos de las elecciones. En cuanto a la reducción normativa, está la ausencia del derecho a voto de los chilenos extranjeros y el nuevo proyecto de ley que consagra el voto voluntario. En cuanto a la reducción fáctica están tanto el ausentismo electoral de más dos millones de personas debido a la ausencia de inscripción automática, como la desproporción de género en los cargos electos.

En cuanto a la democracia ciudadana, ella alude a dos subdimensiones. Por un lado, en la cuestión de los derechos civiles, políticos, económico-sociales y culturales, Chile presenta una relativa adecuación a los tratados y declaraciones de la comunidad internacional, con excepción de los derechos laborales. No así en lo referido a los derechos específicos de la mujer, de las minorías sexuales y de los pueblos indígenas. La desigualdad respecto de la vigencia de derechos entre estas categorías se acompaña 
de una gran desigualdad sustantiva, es decir, de la base material para el ejercicio de los derechos. El problema de la desigualdad se vuelve crítico cuando se examinan: la esfera laboral y el poder diferencial de trabajadores y empleadores (institucionalidad laboral, negociación colectiva, sindicalización); la educación (inequidad educacional que lleva a diferenciales de capital cultural que pueden afecta la democracia ciudadana y que se expresa en indicadores como el gasto y rendimiento diferenciales en educación); la libertad de expresión y el derecho a la información (junto a la liberalización de la normativa heredada de la dictadura, se da la concentración de los medios vinculados al poder económico empresarial).

Por otro lado, la segunda dimensión que refiere a la cuestión de la participación ciudadana tiene, a su vez, dos rasgos básicos. El primero es una situación caracterizada por la existencia de instancias informales y esporádicas de participación, combinada con la inexistencia de una legislación e institucionalización de la misma a niveles locales, regionales y nacionales. El segundo rasgo es la existencia de poderes fácticos que limitan la participación ciudadana y el ejercicio de los derechos, lo que en el caso de poderes fácticos de jure como el caso del Tribunal Constitucional ha impedido la adopción de algunas políticas de promoción y protección de derechos sexuales y reproductivos.

En síntesis, la democracia chilena, analizada a través de las dimensiones constitucional, electoral y ciudadana, presenta la contradicción entre los grandes avances conseguidos bajo los gobiernos de la Concertación y las debilidades en las tres dimensiones. Estas debilidades se explican por los límites fundantes en la soberanía popular observados a partir de la Constitución, que consagró la exclusión política a través del sistema binominal, de lo que se derivan los límites de la democracia electoral. Los problemas asociados a la participación electoral (sujeta a restricciones fácticas y normativas) surgen en un diseño institucional deficiente, que no establece garantías de participación e integración electoral. Asimismo, la dimensión ciudadana de la democracia se enfrenta a problemas de derechos civiles específicos de las minorías, desigualdades socioeconómicas, participación electoral y ausencia de instituciones de participación.

Lo anterior permite sustentar la hipótesis de que pese al éxito registrado por Chile en términos internacionales con respecto a los indicadores sobre calidad democrática, aún subsiste una democracia incompleta. Ello no puede ser despachado con el argumento que toda democracia real es perfectible, porque se trata de elementos constituivos del régimen vigente que, más allá de la vida democrática que el país experimenta, le impiden ser considerado estrictamente como plenamente democrático.

\section{BIBLIOGRAFÍA}

Altman, David. 2007. "Régimen de Gobierno y Sistema de Partidos en Chile". Instituto de Ciencia Política. Pontificia Universidad Católica de Chile.

Ackerman, Bruce. 1998. "We the people. Transformations". Harvard University Press: Cambridge and London.

Aylwin, José. 2009. "Política indígena y "re-conocer". Entre el discurso y la realidad". Revista Mensaje mayo 2009, Santiago, $\mathrm{N}^{\circ} 578$. 
CEPAL. 2007. Panorama Social de América Latina.

Constitución Política de la República de Chile. 2005. Diario Oficial 19 Septiembre www.bcn.cl

Consejo Asesor Presidencial de Trabajo y Equidad. 2008. “Encuesta acerca de las percepciones sobre relaciones laborales y equidad en Chile". Santiago de Chile. Documento web: http://www.trabajoyequidad. $\mathrm{cl} /$ view/viewArticulos.asp?idArticulo $=107$

De la Maza, Gonzalo. 2009. "Estado actual y desafíos para la institucionalización de la Participación ciudadana en Chile". En G. De la Maza y D. Flores (ed.), Gestión Municipal Participativa. Universidad de Los Lagos, abril 2009.

Caro, P. Wilson, A. Hernández, T. 2004. Problemáticas que Enfrentan las Mujeres en el Campo Laboral. Agenda Ciudadana, Responsabilidad Social Empresarial y Género. Red Puentes, RSE Chile. Febrero 2004.

Correa, Sofía y otros. 2001. Documentos del Siglo XX chileno, Editorial Sudamericana.

Encuesta de Caracterización Socioeconómica Nacional (CASEN). 2006. Informe "Trabajo e Ingresos". Disponible en www.casen.cl

Garretón, Manuel Antonio. 2003. Incomplete Democracy. Political Democratization in Chile and Latin America. Chapel Hill: University of North Carolina Press.

Garretón, Manuel Antonio. 2007. Del post-pinochetismo a la sociedad democrática. Política y globalización en el Bicentenario. Santiago Random House, Mondadori.

Garretón, Roberto. 2009. Una Constitución democrática es posible. Le Monde Diplomatique Chile No 90.

Garretón, Roberto. 2009. Los tribunales con jurisdicción penal durante la transición a la democracia en Chile. En Justicia transicional en Iberoamérica. Centro de Estudios Políticos y Constitucionales, Madrid, 2 (2009).

Huneeus, Carlos (comp.). 2006. La reforma del sistema binominal en Chile. Una contribución al debate. Konrad Adenauer Stiftung, Santiago, 2006).

Instituto Nacional de Estadísticas. Compendio Estadístico de la población ocupada según rama de trabajo. Disponible como documento web en: http:/ / www.ine.cl/canales/chile_estadistico/mercado_del_ trabajo/empleo/series_estadisticas/empalmadas/rama1998.php.

La Tercera. 2008. "Cámara de Diputados rechaza proyecto de Ley de reforma al sistema binominal del gobierno". Noticia publicada con fecha miércoles 7 de mayo de 2008. Sitio web: www.latercera.cl

Linz, Juan. 1973. “The Future of an Authoritarian Situation or the Institutionalization of an Authoritarian Regime: Brazil", in Alfred Stepan ed., Authoritarian Brazil: Origins, Politics, and Future, New Haven, Yale University Press, pp. 232-254.

Ministerio de Vivienda y Urbanismo y Observatorio Social. Universidad Padre Alberto Hurtado. 2008. "Recuperando barrios de Santiago". Folleto. Santiago.

Moulian, Tomás. 1997. Chile actual: Anatomía de un mito, Editorial LOM.

O'Donnell, Guillermo. 1977. Contrapuntos. Ensayos escogidos sobre autoritarismo y democratización. Buenos Aires: Paidós.

Ominami, Carlos. 2005. "Propuesta de Agenda Corta: establecimiento de una alianza Birregional entre A. Latina y el Caribe y la Unión Europea". Publicado con fecha 15/06/2005.

Disponible en: http://www.senado.cl/prontus_galeria_noticias/site/artic/20080125/ pags/20080125152937.html

Organización de Naciones Unidas. Oficina del Alto Comisionado para los Derechos Humanos. “Instrumentos Internacionales de Derechos Humanos". Documento web: http://www.derechos.org/nizkor/ley/.

OMS. 2003. Migración Internacional, Salud y Derechos Humanos. $\mathrm{N}^{\circ}$ 4, diciembre 20.

Portal Valenzuela, Belfor. 2008. "Proposición Metodológica para la Evaluación del Impacto Ambiental de los Planes Reguladores Comunales". Disponible en sitio web: http://www.vrid.usach.cl/pub/ Belfor\%20Portal.pdf USACH

Portales, Felipe. 2000. Chile, una democracia tutelada. Editorial Sudamericana 2000.

Ruiz Tagle, Pablo, Cristi, Renato. 2006. La República en Chile. Teoría y Práctica del Constitucionalismo Republicano, Editorial LOM.

Sabatini, Francisco \& Sepúlveda, Claudia \& Blanco, Hernán. 2009. “Participación Ciudadana para enfrentar conflictos medioambientales. Desafíos para el Sistema de Evaluación de Impacto Medioambiental". 
Disponible en el sitio web: http:/ / www.cipma.cl/Participacion_ciudadana_conflictos_ambientales.pdf Universidad Diego Portales. Facultad de Derecho. Fundación John Merck. 2008. "Informe anual sobre Derechos Humanos en Chile 2008". Ediciones UDP.

Universidad Diego Portales. Centro de Derechos Humanos. 2007. Reporte a la Oficina del Relator Especial para la Libertad de Expresión de la CIDH en el contexto de la Evaluación sobre el estado de la Libertad de Expresión en la región. Investigación a cargo de Mayra Feddersen M. Santiago de Chile.

Zamorano, S. 2009. "Ley de Acceso a la Información. El nuevo poder ciudadano". Revista Mensaje, Santiago, marzo-abril 2009. $\mathrm{N}^{\circ} 577$.

Manuel Antonio Garretón M. Sociólogo formado en la Universidad Católica de Santiago y Doctorado en l'Ecole des Hautes Etudes en Sciences Sociales. París. Investigaciones y cursos impartidos sobre sociología política, cultura, Estado, actores y movimentos sociales, educación y desarrollo de las ciencias sociales, políticas públicas. Autor de más de cuarenta libros entre autoría, coautoría, ediciones, compilaciones y más de doscientos artículos en revistas, traducidos en varias lenguas. Entre los últimos libros: La sociedad en que vivi(re)mos. Introducción sociológica al cambio de siglo (2000). The incomplete democracy. Studies on politics and society in Latin America and Chile (2003). Del post-pinochetismo a la sociedad democrática. Globalización y Política en el bicentenario (2007). En la actualidad y desde 1994 es Profesor Titular del Departamento Sociología de la Facultad de Ciencias Sociales de la Universidad de Chile. Es también Profesor de la Escuela de Política y Gobierno de la Universidad Nacional San Martín, Buenos Aires. Premio Nacional de Ciencias Sociales y Humanidades (2007).

(E-mail: magarret@uchile.cl)

Roberto Garretón Licenciado en Ciencias Jurídicas Universidad de Chile. Abogado. Defensor de derechos humanos en Chile durante la dictadura del General Pinochet (1973-1990), miembro de la Vicaría de la Solidaridad. Embajador del gobierno de Patricio Aylwin ante los organismos internacionales de derechos humanos. Vicepresidente de la Comisión de Derechos Humanos de Naciones Unidas y de la Conferencia Mundial de Derechos Humanos de Viena (1993). Integrante del Grupo de Trabajo sobre Detenciones Arbitrias de las Naciones Unidas (1991-2000) y desde 2008 Relator Especial de las Naciones Unidas sobre los derechos humanos en el ex Zaire, actualmente República Democrática del Congo (1994-2001). Representante de la Alta Comisionada para los Derechos Humanos para América Latina y el Caribe (2001-2005). Comisionado de la Comisión Internacional de Juristas, ONG internacional, fundada en 1952, con sede en Ginebra (desde 2008). Misiones de derechos humanos en más de quince países. Integrante del Consejo Asesor de las Naciones Unidas sobre Prevención de Genocidios (desde 2006). Premios: Monseñor Leonidas Proaño, de ALDHU (1989); Ruth Pearce, Servicio Internacional de Derechos Humanos Ginebra 1993: Palme Nationale des Droits de l'Homme, del Consejo Nacional de Derechos Humanos en Islam, República Democrática del Congo (1999). Oficial de la Legión de Honor (Francia, 2003).

(E-mail: garretonroberto@gmail.com) 